\title{
Nano-ADEPT Aeroloads Wind Tunnel Test
}

\author{
Brandon Smith, Bryan Yount, Carl \\ Kruger, Chad Brivkalns, Alberto \\ Makino, Alan Cassell, Kerry Zarchi, \\ Ryan McDaniel, James Ross, Paul \\ Wercinski, Ethiraj Venkatapathy \\ NASA Ames Research Center \\ M/S 229-1 \\ Moffett Field, CA 94035 \\ 650-604-6578 \\ Brandon.P.Smith@nasa.gov
}

\begin{abstract}
A wind tunnel test of the Adaptable Deployable Entry and Placement Technology (ADEPT) was conducted in April 2015 at the US Army's 7x10 Foot Wind Tunnel located at NASA Ames Research Center. Key geometric features of the fabric test article were a $0.7 \mathrm{~m}$ deployed base diameter, a $70^{\circ}$ half-angle forebody cone angle, eight ribs, and a nose-to-base radius ratio of 0.7 . The primary objective of this wind tunnel test was to obtain static deflected shape and pressure distributions while varying pretension at dynamic pressures and angles of attack relevant to entry conditions at Earth, Mars, and Venus. Other objectives included obtaining aerodynamic force and moment data and determining the presence and magnitude of any dynamic aeroelastic behavior (buzz/flutter) in the fabric trailing edge.
\end{abstract}

All instrumentation systems worked as planned and a rich data set was obtained. This paper describes the test articles, instrumentation systems, data products, and test results. Four notable conclusions are drawn. First, test data support adopting a pre-tension lower bound of $10 \mathrm{lbf} / \mathrm{in}$ for Nano-ADEPT mission applications in order to minimize the impact of static deflection. Second, test results indicate that the fabric conditioning process needs to be reevaluated. Third, no flutter/buzz of the fabric was observed for any test condition and should also not occur at hypersonic speeds. Fourth, translating one of the gores caused ADEPT to generate lift without the need for a center of gravity offset. At hypersonic speeds, the lift generated by actuating ADEPT gores could be used for vehicle control.

\section{TABLE OF CONTENTS}

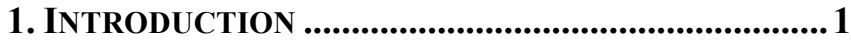

2. TEST APPROACH .................................................2

3. Common INSTRUMENTATION ................................. 3

4. FABRIC TEST ARTICLE............................................ 3

5. SOLID TEST ARTICLE .......................................... 8

6. STATIC LOADS AND DEFLECTIONS.......................9

7. DYNAMIC FLUID STRUCTURE INTERACTION...... 14

8. ASYMMETRIC SHAPE ............................................. 15

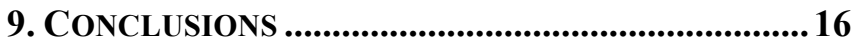

10. FUTURE WORK........................................................ 17

Appendix A. Test Matrix (Selected Points).. 17

APPENDIX B. DATA REDUCTION................................ 18

ACKNOWLEDGEMENTS .........................................20

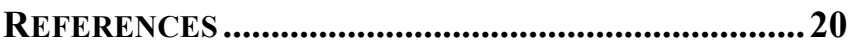

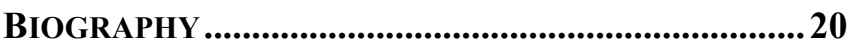

978-1-4673-7676-1/16/\$31.00 C2016 IEEE

\author{
Gregory Swanson \\ AMA, Inc. \\ NASA Ames Research Center \\ Moffett Field, CA 94035 \\ Nili Gold \\ US Army AFDD \\ NASA Ames Research Center \\ Moffett Field, CA 94035
}

\section{INTRODUCTION}

\section{ADEPT Background}

NASA's 2015 technology roadmap identifies mechanicallydeployed entry systems as a technology candidate with mission enabling benefits [1]. Adaptable Entry and Placement Technology (ADEPT) is one such technology, using a 3D woven carbon fabric that serves both as thermal protection and primary structure. Specific missions identified by the roadmap that ADEPT could enable are large payload delivery to the Martian surface, ISS down-mass, and crewed Earth return beyond low Earth orbit. Recent work has shown that ADEPT could also have enabling science benefits for small spacecraft missions that are riding along as secondary payloads and in need of a low-volume deployable entry system [2]. These "Nano-ADEPT" entry vehicles are targeted for systems with an entry mass of less than $15 \mathrm{~kg}$ and a payload mass on the order of $5 \mathrm{~kg}$.

\section{Motivation for Test}

This wind tunnel test is one component of a broader strategy to advance the technology readiness level (TRL) of ADEPT to a maturity level of TRL5. A critical requirement for ADEPT to reach TRL5 is an understanding of the factors influencing fluid-structure interaction of the 3D woven carbon fabric and the entry flow field. This is critical because the aerothermal heating and aerodynamic forces imparted on the vehicle can be sensitive to the degree of static deflection imparted in the fabric gores by the entry flow field. The primary motivation for this wind tunnel test was the generation of deflected shape data as a function of key design parameters for ADEPT missions: aerodynamic load, angle of attack, and the amount of pre-tension put in the fabric prior to atmospheric entry. These data are being used to improve structural modeling tools used in the design of ADEPT for multiple mission architectures.

\section{Test Objectives}

There were three objectives of this wind tunnel test:

1. Obtain static deflected shape while varying pre-tension at dynamic pressures and angles of attack relevant to entry conditions at Earth, Mars, and Venus

2. Observe onset of detrimental aeroelastic behavior as a function of pre-tension and dynamic pressure 
3. Obtain aerodynamic forces and moments as a function of pre-tension, angle of attack, and dynamic pressure

A Note on Pre-Tension-Tension in the carbon fabric is caused by two primary sources: "pre-tension" resulting from the mechanical deployment of ADEPT prior to atmospheric entry and additional tension resulting from the aerodynamic load during entry. Fabric tension will also change as a result of thermal expansion of the fabric and supporting structure. Pretension is controlled through design of the mechanical structure that supports the carbon fabric and the deployment system used to achieve the desired shape prior to entry. Achieving higher pre-tension settings requires higher deployment forces resulting in a heavier actuation system. We desire to only have these actuation forces as high as they need to be to meet the requirements of a specific mission. For atmospheric entries that are more aerothermally benign, such as Mars entries, less pre-tension may be needed than entries that are more aerothermally extreme, such as Venus entries.

\section{TeST APPROACH}

\section{Wind Tunnel Description}

The 7-by 10 -foot wind tunnel (referred to as the " $7 \times 10$ tunnel" in this document) is a Mach $0.3(\sim 300 \mathrm{ft} / \mathrm{s}$ at sea level) subsonic, atmospheric, closed-circuit, single return tunnel with a closed rectangular test section measuring $7 \mathrm{ft}$. wide, $10 \mathrm{ft}$. high, and $15 \mathrm{ft}$. long. It is located at NASA Ames Research Center in Moffett Field, CA and is operated by the US Army Aviation Development Directorate - AFDD (Aeroflightdynamics Directorate).

\section{Traceability to Design Reference Missions}

The test matrix was derived from the above test objectives considering the mission application space and the capabilities of the $7 \times 10$ tunnel. Two test articles were subjected to aero loads in the wind tunnel in order to achieve the test objectives: one "solid" test article and one "fabric" test article. The fabric test article used a fabric skirt comprised of woven carbon fabric gores stitched together with carbon yarn and resininfused in the joints over the ribs. These processes are very similar to what would be used for a future flight article. The pre-tension of the fabric in the fabric test article is adjustable so that deflection measurements may be correlated to fabric pre-tension, dynamic pressure, and angle of attack. The purpose of the solid test article is to obtain the forebody pressure distribution and aerodynamic loads on a known undeflected rigid surface. This measurement simulates a fabric test article with infinite pre-tension and can be used to anchor the pressure and deflection measurements made on the fabric test article. The solid test article is also used to check out the wind tunnel test configuration (instrumentation settings, blockage, mechanical resonance, etc.) prior to testing the more valuable fabric test article. More details on the design of the solid and fabric test articles are described in a subsequent section of this paper.

Prior to testing, an analysis was completed to evaluate the ability to match aeroloads in the $7 \times 10$ tunnel test with those experienced during key Nano-ADEPT Design Reference Missions (DRM). In the mission environment, Nano-ADEPT will pass through peak dynamic pressure at a hypersonic Mach number. Peak dynamic pressure will occur near $0^{\circ}$ angle of attack for a ballistic mission. A guided or lifting configuration may pass through peak dynamic pressure at some non-zero angle of attack. In order to compare the drag force on the fabric structure in the $7 \times 10$ tunnel with the flight environments, we must consider the difference between the hypersonic drag coefficient, $\left(C_{D}\right)_{h}$, and the subsonic drag coefficient, $\left(C_{D}\right)_{s}$. Table 1 gives estimates of the drag coefficient for this configuration of Nano-ADEPT (8-sided $70^{\circ}$ forebody). The subsonic drag coefficients in this table have been updated from the pre-test predictions to averages of the measured drag coefficient from this wind tunnel test. The ratio $\left(C_{D}\right)_{h} /\left(C_{D}\right)_{s}$ can be used to compute the equivalent subsonic dynamic pressure required to match the hypersonic drag force as:

$$
q_{\text {subsonic }}=q_{\text {hypersonic }} \frac{\left(C_{D}\right)_{h}}{\left(C_{D}\right)_{s}}
$$

Table 1. General comparison of hypersonic and subsonic drag coefficient for $70^{\circ}$ ADEPT.

\begin{tabular}{|c|c|c|c|}
\hline AoA & $\begin{array}{c}\text { Hypersonic } \\
\left(\mathrm{CD}_{\mathrm{H}}\right)\end{array}$ & $\begin{array}{c}\text { Subsonic } \\
\left(\mathrm{CD}_{\mathrm{S}}\right)\end{array}$ & $\mathrm{CD}_{\mathrm{H}} / \mathrm{CD}_{\mathrm{S}}$ \\
\hline \hline $0^{\circ}$ & 1.7 & 1.05 & 1.6 \\
\hline $10^{\circ}$ & 1.6 & 1.03 & 1.6 \\
\hline $20^{\circ}$ & 1.4 & 1.00 & 1.4 \\
\hline
\end{tabular}

Table 1 implies that a higher dynamic pressure is required in a subsonic wind tunnel to match the drag force experienced at hypersonic speeds. The maximum dynamic pressure that was achieved in the $7 \times 10$ tunnel is 100 psf. This was the dynamic pressure at which the $7 \times 10$ tunnel reached its maximum power capability. Table 2 shows the required dynamic pressure ("Q") in order to match peak drag force expected for three DRMs. Comparing the achieved dynamic pressures with the mission values gives an indication of how relevant the dynamic pressure setting is to a given DRM peak drag force (note Test Objective \#1). Italics indicate conditions that were reached in this wind tunnel test. The table also shows the sensitivity of the aeroloads to the entry mass, and thus gives some indication of test relevance compared to potential missions. The table shows that this test covers all entries from low Earth orbit (LEO) DRMs and Mars secondary DRMs below $\sim 12 \mathrm{~kg}$ entry mass. Clearly this test was not fully bounding for all missions in terms of dynamic pressure and future experimental or analytical efforts are required to extend the dynamic pressure envelope. The need for more testing is especially high for Venus secondary DRMs where an entry mass of $5 \mathrm{~kg}$ (the range covered by this test) is not realistic. Preferably these future ground tests would be conducted at a supersonic Mach number in order to better match pressure distribution as well as drag force (e.g. Unitary Plan $9 \mathrm{ft}$. x $7 \mathrm{ft}$. Wind Tunnel at NASA Ames). 
Table 2. Subsonic wind tunnel dynamic pressure required to match peak drag force for a given DRM. Blue italics indicate conditions that were reached in this wind tunnel test.

\begin{tabular}{|c|c|c|c|}
\hline \multirow{2}{*}{ Entry mass, $\mathrm{kg}$} & \\
\hline & 15 & 10 & 5 \\
\hline \multirow[t]{2}{*}{ Ballistic coefficient, $\mathrm{kg} / \mathrm{m}^{2}$} & 22.5 & 15 & 7.5 \\
\hline & \multicolumn{3}{|c|}{ Mars Secondary DRM } \\
\hline DRM Peak Q, psf & 75 & 52 & 29 \\
\hline Q required @ $0^{\circ} \mathrm{AoA}, \mathrm{psf}$ & 121 & 84 & 47 \\
\hline Q required@10 AoA,psf & 117 & 81 & 45 \\
\hline \multirow[t]{2}{*}{ Q required@20AoA,psf } & 105 & 73 & 41 \\
\hline & \multicolumn{3}{|c|}{ Entry from LEO DRM } \\
\hline Peak dynamic pressure, psf & 44 & 29 & 15 \\
\hline Q required@ $@ 0^{\circ}$ AoA, psf & 71 & 47 & 24 \\
\hline Q required@10AoA,psf & 69 & 45 & 23 \\
\hline \multirow[t]{2}{*}{ Q required@20AoA,psf } & 62 & 41 & 21 \\
\hline & \multicolumn{3}{|c|}{ Venus Secondary DRM } \\
\hline Peak dynamic pressure, psf & 155 & 109 & 56 \\
\hline Q required@0 AoA,psf & 251 & 176 & 91 \\
\hline Q required@10AoA,psf & 242 & 170 & 87 \\
\hline Q required@20AoA,psf & 217 & 153 & 78 \\
\hline
\end{tabular}

\section{Test Matrix Overview}

The baseline test matrix is given below in Table 1. Events during testing led to a significant rework of this test matrix during the week of testing. Note that the 120 psf condition was not achieved due to wind tunnel power limitations. Throughout this paper there are references to test "runs" and test "points". A run consists of a parameter sweep at several "points". Appendix A provides run information for all of the test runs and points referred to in this document.

Table 3. Baseline test matrix.

\begin{tabular}{|c|c|c|c|}
\hline $\begin{array}{l}\text { Test } \\
\text { Article }\end{array}$ & Configuration & $\operatorname{AoA}\left({ }^{\circ}\right)$ & $Q$ (psf) \\
\hline Solid & $\mathrm{n} / \mathrm{a}$ & $\begin{array}{c}0,10,20 \\
-20,-10,0\end{array}$ & $\begin{array}{c}10,20,50 \\
75,100,120\end{array}$ \\
\hline Fabric & $20 \mathrm{lbf} /$ in nut setting & $\begin{array}{l}0,10,20 \\
-20,-10,0\end{array}$ & $\begin{array}{c}10,20,50 \\
75,100,120\end{array}$ \\
\hline Fabric & $10 \mathrm{lbf} /$ in nut setting & $\begin{array}{c}0,10,20 \\
-20,-10,0\end{array}$ & $\begin{array}{c}10,20,50 \\
75,100,120\end{array}$ \\
\hline Fabric & $5 \mathrm{lbf} /$ in nut setting & $\begin{array}{c}0,10,20 \\
-20,-10,0\end{array}$ & $\begin{array}{c}10,20,50 \\
75,100,120\end{array}$ \\
\hline Fabric & $\begin{array}{c}2 \text { lbf/in ("taut") nut } \\
\text { setting }\end{array}$ & $\begin{array}{c}0,10,20 \\
-20,-10,0\end{array}$ & $\begin{array}{c}10,20,50 \\
75,100,120\end{array}$ \\
\hline
\end{tabular}

\section{COMMON INSTRUMENTATION}

The solid test article and the fabric test article share a common interface and can be interchanged without removing the balance from the test article support. Test article forces and moments were measured via the balance. Both test articles were instrumented similarly. They both have an array of 36 pressure taps on the nose cap and on the fabric gores. The solid test article has an extra four pressure taps to assist in post-test computational fluid dynamics (CFD) simulation validation. There were two accelerometers mounted to the sting to measure the test article support frequency. Finally, an Mk.2A internal balance with 1.75 inch diameter was used at the model to sting interface to measure the forces and moments applied during the wind tunnel test series. Figure 1 shows the location of the balance relative to the test article aerodynamic surfaces.

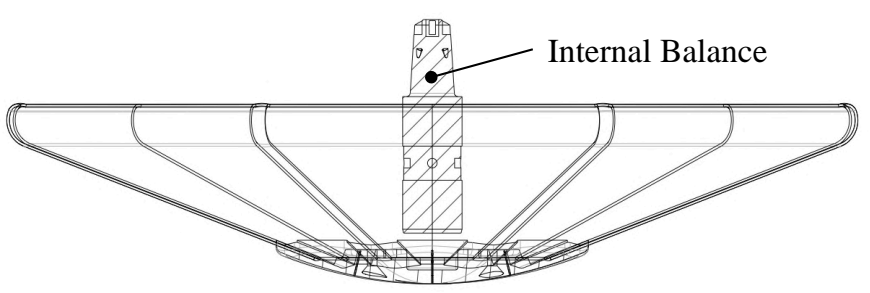

Figure 1. Section view showing location of the Mk.2A internal balance used on both the solid and fabric test articles. The balance center is located $7.16 \mathrm{~cm}(3.82 \mathrm{in}$. from the nose tip.

\section{FABric Test ARTICle}

The fabric test article is comprised of eight ribs that are deployed like an umbrella to create tension in the carbon fabric. The geometry is an octagonal pyramid with rib-tip-torib-tip length of $0.70 \mathrm{~m}$ (27.6 in) and mid-gore-to-mid-gore length of $0.66 \mathrm{~m}$ (25.9 in). The nosecap geometry (3D-printed) is a sphere cap blended to an octagonal pyramid at the interface with the fabric gores.

The fabric test article has a small range of deployment motion sufficient to change the fabric pretension from slack to 20 lbf/in. Figure 2 shows the fabric test article before and after integration of the carbon fabric with the metallic skeleton. Note that the carbon fabric skirt has been infused with resin at the eight seam locations in order to more closely match flight processes. The resin has the physical effect of hardening the seams while also making them more resistant to degradation from the aerothermal environment. Each rib is moved by a pair of struts, which are attached at the other end to a moving ring that circles the center body. A large central gland nut located at the base of the struts can be tightened or loosened to push the moving ring and adjust pre-tension. Nut positions that provided a known pre-tension were marked prior to wind tunnel testing based on pre-test calibration measurements. These known pre-tensions were $20 \mathrm{lbf} / \mathrm{in}, 10 \mathrm{lbf} / \mathrm{in}, 5 \mathrm{lbf} / \mathrm{in}$ and $2 \mathrm{lbf} /$ in $(2 \mathrm{lbf} / \mathrm{in}=$ "taut" nut setting). Note that the ribs and struts (two per rib) are oversized in strength compared to what they would be in flight in order to comply with wind tunnel safety requirements and allow for the use of some commercially available parts. 

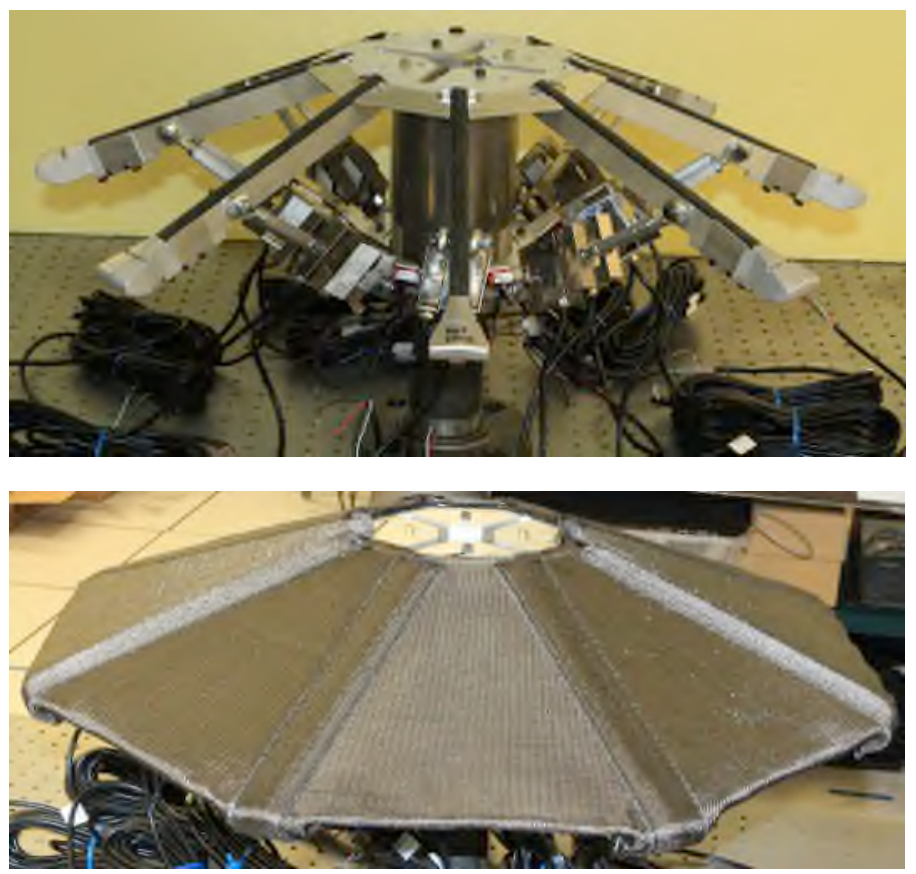

Figure 2. Fabric test article rigid skeleton consisting of ribs, struts, and centerbody (top); fabric skirt integrated onto rigid skeleton (bottom).

Figure 3 shows two views of the completed fabric test article installed in the $7 \times 10$ tunnel. Some of the instrumentation can be seen on the rear view. Pressure tubes are visible at each of the gores. The blue lights are from light-emitting diodes (LED) located on the amplifiers of each strut load cell. The large wire harness from the strut load cells is fastened to the sting using wire ties. The front view in Figure 3 shows the nose cap, pressure taps, and photogrammetry speckle paint. Note that one of the gores was left unpainted in order to assess the effect of the photogrammetry speckle paint on the stiffness of the fabric. The four red circles on the nose are bolt countersinks filled with a clay-wax material known as "clax". The clax is also used as a seal in between the nose and the carbon fabric skirt.

Bally Ribbon Mills in Bally, PA manufactured the six-layer carbon fabric used for the fabric test article. The fabric was conditioned in the weft direction (rib-to-rib) using an Instron machine until the load/deflection curve no longer showed hysteresis. The clamps shown in Figure 5 were used to grip the fabric and perform the conditioning. The conditioning occurred prior to cutting the fabric into the gore shape. The individual gores were then stitched together by Thin Red Line Aerospace in Chilliwack, B.C., Canada.
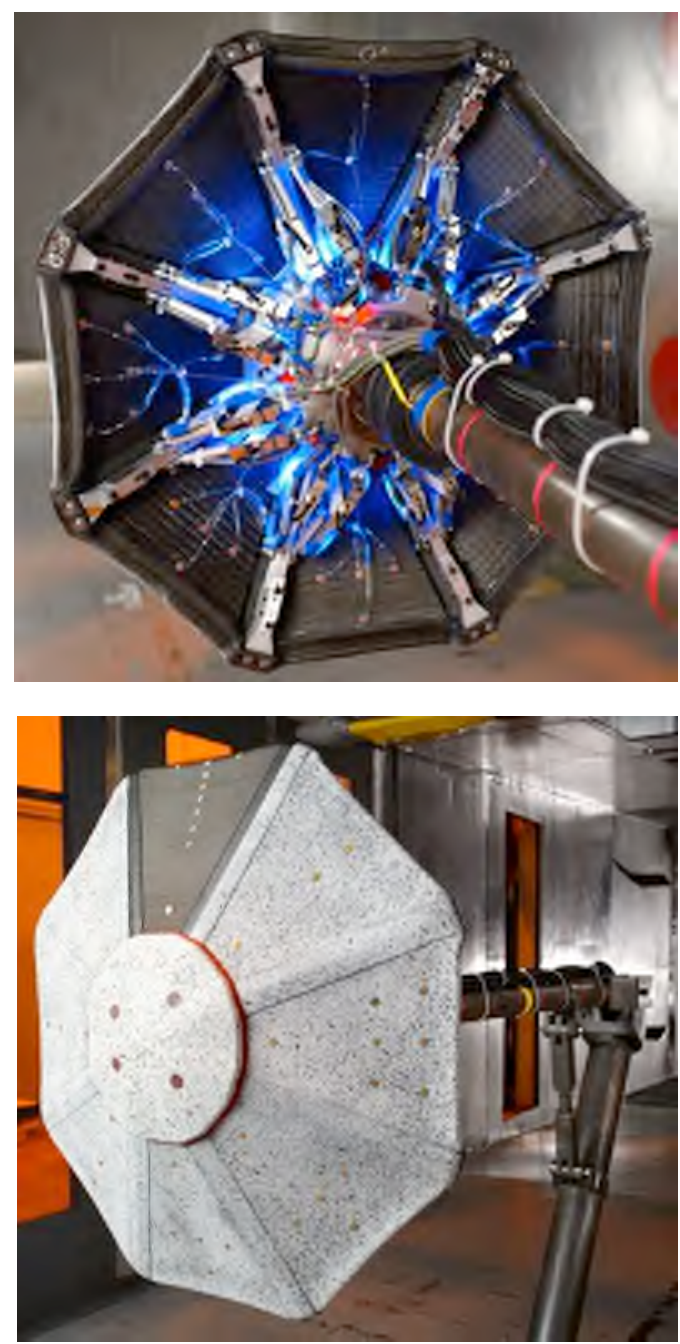

Figure 3 Fabric test article rear view (top) and front view (bottom) installed in 7x10 tunnel.

\section{Fabric Pre-Tension Summary}

A method that employs measuring out-of-plane displacement caused by a known load, and comparing that with displacement results from an equivalent sample under known tension levels was used to determine pre-tension levels in the model. This process is depicted below in Figure 4.

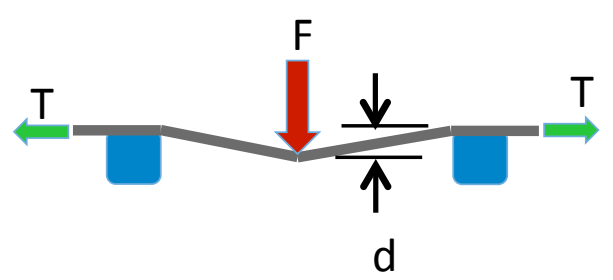

Figure 4. Displacement caused by known out-of-plane force.

The indirect tension measurement method used a calibration rig (Figure 5- left) to determine deflection versus tension curves for the equivalent fabric sample, and a deflection measurement tool (Figure 5- right) for measuring deflection on the wind tunnel model (and thereby calculating model pretension). Deflection measurements were taken at a single location (point of maximum deflection predicted by analysis) 
for each gore to determine the representative tension in that gore.
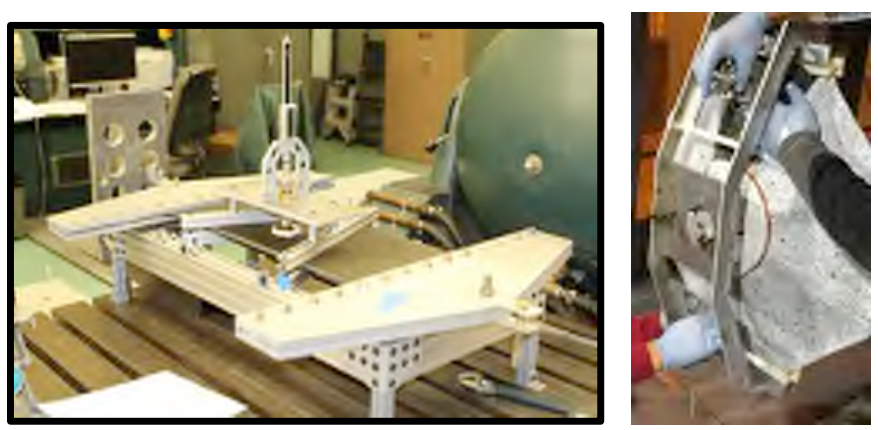

Figure 5. Calibration rig (left) and deflection measurement tool (right).

Difficulty in matching geometry \& support conditions, changes in the fabric behavior with handling, shifting of the fabric \& skeleton components during model adjustments, limited time to take multiple repeat measurements, and some issues with the measurement process itself resulted in somewhat poorer than desired accuracy between the calibration curves and tension measurements taken on the wind tunnel model. Despite these issues, the indirect tension measurement method provided a means to quantify the overall model fabric pre-tension and ensure that the tension range called out in the test plan was covered.

This indirect tension measurement method was used to determine the model adjustments necessary to achieve the desired model fabric pre-tension settings of approximately 20 lbf/in, $10 \mathrm{lbf} / \mathrm{in}, 5 \mathrm{lbf} / \mathrm{in}$ and "taut". It was also used to check model pre-tension between selected wind tunnel test runs.

\section{Fabric Test Article Instrumentation}

The fabric test article employed multiple sensor systems to measure strut loads, gore deflection, and surface pressure distribution to characterize the performance under aerodynamic loading. These sensors were actively monitored and recorded throughout the test series. The following sections describe each instrumentation system and methodology. Figure 6 below shows the general instrumentation layout for the fabric test article. Approximate locations of the pressure ports, string potentiometers, and load cells are depicted. Individual gores are identified by their angular location relative to the top gore located at $0^{\circ}$.

Pressure port locations were positioned at three different radial locations: nose transition, max deflection, and trailing edge. These location names are only descriptions of the targeted area and not exact locations. Pressure tap layout was determined by balancing a number of factors. The number of pressure taps was limited by the Scanivalve system used by the $7 \times 10$ facility, so every gore could not be instrumented with the same density. It was expected that the pressure distribution on the test article would have top-bottom symmetry as well as leftright symmetry. Because of this, pressure taps were focused in one quadrant of the test article $\left(90^{\circ}, 135^{\circ}\right.$, and $180^{\circ}$ gores $)$. The $90^{\circ}$ gore was instrumented most heavily because the photogrammetry system was expected to generate the best deflection maps on this gore (note that the photogrammetry system was located on the same side of the tunnel as the $90^{\circ}$ gore).

Two data systems were used in this wind tunnel test. The $7 \times 10$ facility data system is called "BDAS" and was used to record loads from the internal balance and pressure tap measurements. BDAS also records tunnel environmental factors and computes test article aerodynamic forces based on an input reference length and area. Quantities measured and output by BDAS are the average value over 30 seconds of recorded data for each test point. A second laptop-based data system was used to record data from the string potentiometers and strut load cells. A time-sync channel was connected between BDAS and the laptop-based data system that gave a simple $5 \mathrm{~V}$ output whenever BDAS was recording. This connection allowed data from both systems to be synchronized in post-processing. String potentiometer and strut load cell data were reduced in Matlab by taking an average of the recorded data while BDAS was powered. 


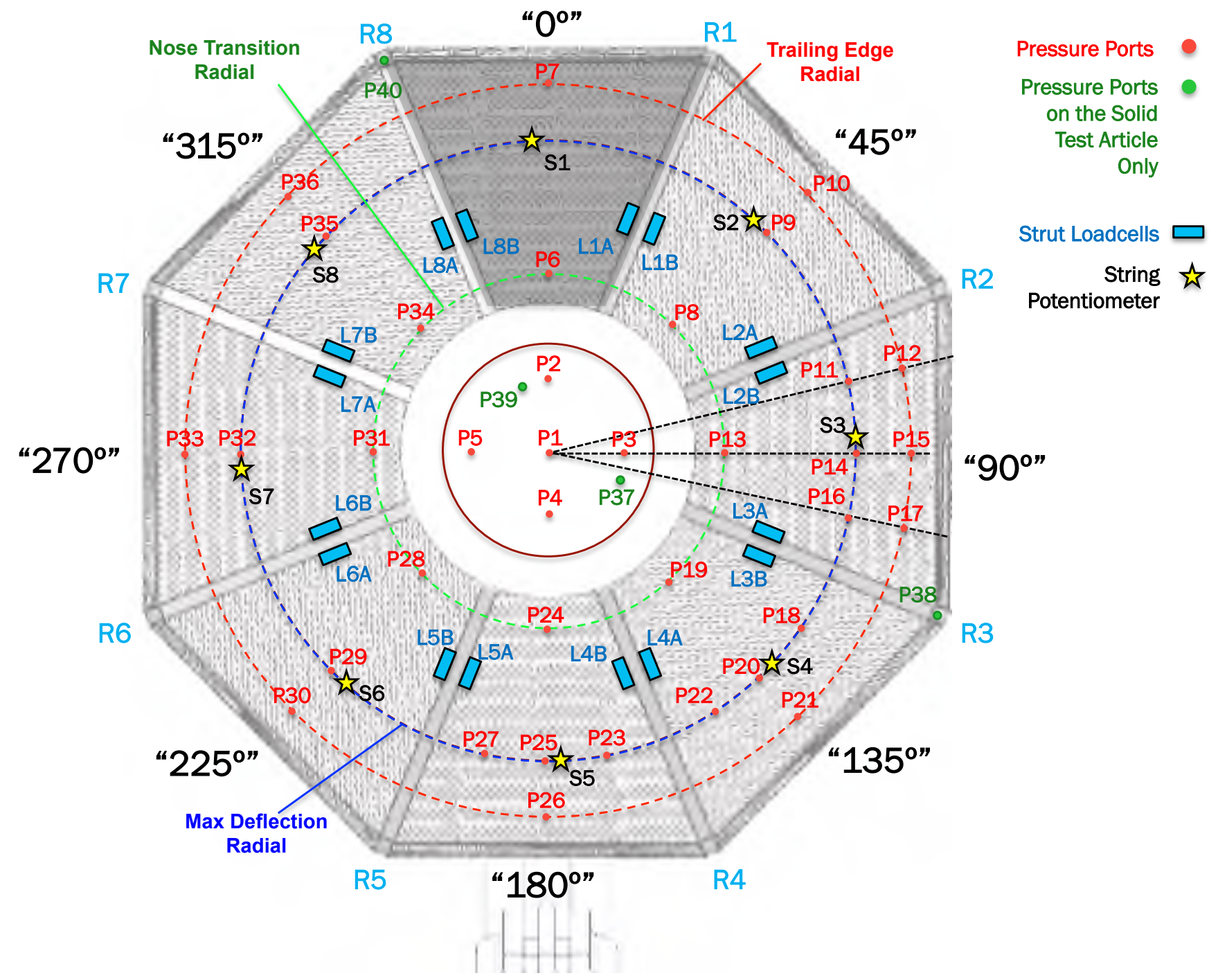

Figure 6. Fabric test article instrumentation layout and naming conventions.

Photogrammetry-An ARAMIS photogrammetry system was used to acquire images and process them to obtain a 3D map of the deflections of the ADEPT test article. The system relies on taking two simultaneous pictures from slightly different angles with respect to the test article in order to reconstruct a stereoscopic image where pixels can be tracked. A series of such pairs of pictures can be used to track displacements.

The main components of the system are shown in Figure 7. The two charge-coupled device (CCD) cameras are mounted on a rigid bar attached to a tripod mount. The controller has the function of triggering the cameras and acts also as an interface to the computer where the image processing software resides. The signal to trigger the cameras was common with the rest of the data acquisition system via a transistor to transistor (TTL) signal controlled by the test operator from the $7 \times 10$ control room. The image acquisition and post processing is controlled with a graphical user interface (GUI) on the computer.

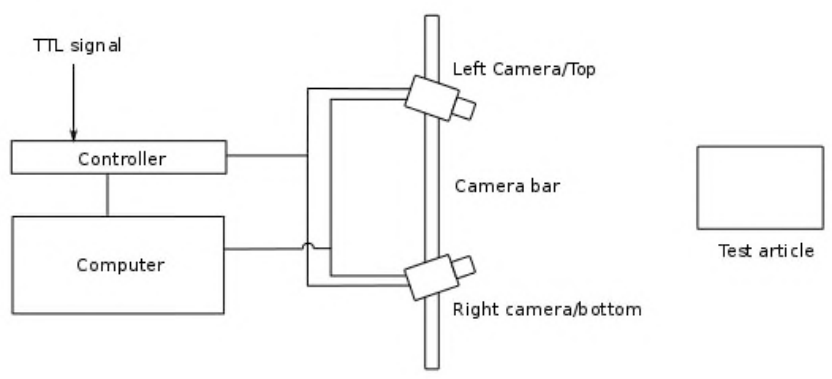

Figure 7. Photogrammetry system schematic. The system is focused on the $45^{\circ}, 90^{\circ}$, and $135^{\circ}$ gores.

All the gores of the test article except one $\left(0^{\circ}\right.$ gore $)$ were painted with a black on white background speckle pattern in order to provide the required reference points to track movements from one picture frame to another. Speckling eases the task to track pixels from one frame to another. The paint was oil-based and the delivery was performed with a spray can. Oil based paint provided the best contrast as opposed to water-based paints. 
The camera system was mounted outside one of the $7 \times 10$ tunnel observation windows as shown in Figure 8. In order to allow an unobstructed view to the test article, a pair of 6 in. diameter holes was drilled in the Plexiglas windows and the cameras were located such as to clear the airstream leaking from these holes. The tripod was weighed down with $20 \mathrm{lb}$. leadshot bags that provided the necessary stability against airstream-induced vibrations. The illumination source was dual; the built-in camera LED spotlights were complemented with a single $20 \mathrm{~W}$ LED light bar located beside the camera bar.

Images were acquired at a rate of 5 frames/s and shutter time was varied between 25.27 and $37 \mathrm{~ms}$ depending on the flow speed in order to prevent blurring of pictures. The shorter shutter times were used for higher flow speeds due to the higher oscillation frequency of the test article. Data was acquired for 5 seconds during the data acquisition window for each flow speed.

Table 4 provides the photogrammetry camera settings. The aperture setting was dictated by the need to provide the necessary depth of field due to the wide variation of the test article to camera distance. However, the smaller aperture prevented the use of frame rates higher than $5 \mathrm{fps}$ due the limited light that could reach the CCD sensors of the cameras.

Table 4. Photogrammetry camera settings.

\begin{tabular}{|c|c|}
\hline Distance to test article (avg) & $1,600 \mathrm{~mm}$ (63 in) \\
\hline Lens, focal distance & $50 \mathrm{~mm}$ \\
\hline Aperture & $\mathrm{f} 16$ \\
\hline
\end{tabular}

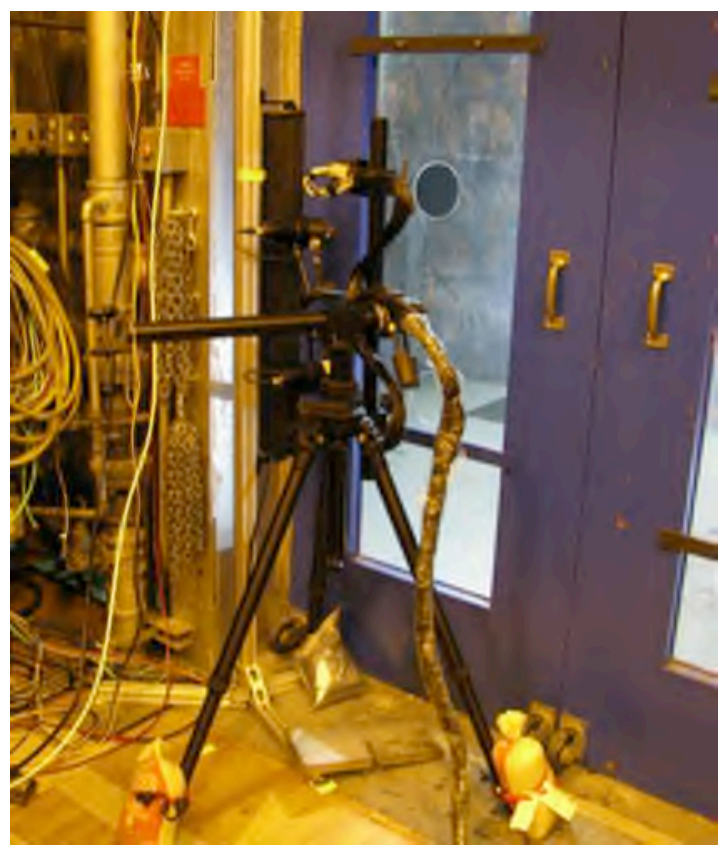

Figure 8. Photogrammetry cameras mounted sideways on a tripod outside the $7 \times 10$ tunnel.
String Potentiometers - To supplement the photogrammetry system, small string potentiometers were used on each of the eight gores. This instrument consists of a string on a spool attached to the centerbody and anchored at a mid-gore location. Figure 9 shows a drawing of the string potentiometers used for this test. The string potentiometers provide a single value for gore deflection at each gore and so are useful for comparing deflection results between gores within a given run. A photograph of a string potentiometer installed in the fabric test article is shown in Figure 10. The stitched attachment was located adjacent to the pressure tap located on the max deflection radial (see Figure 6). Each string potentiometer has a range of $0-1.5 "$ and an accuracy of $\pm .015 "$.
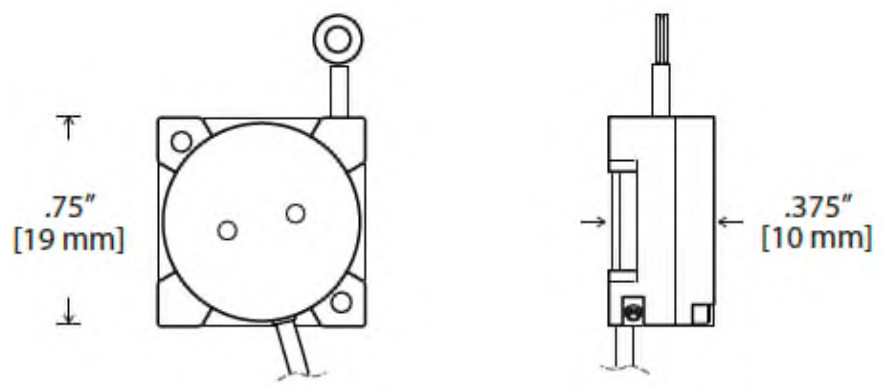

Figure 9. String potentiometers used on the fabric test article.

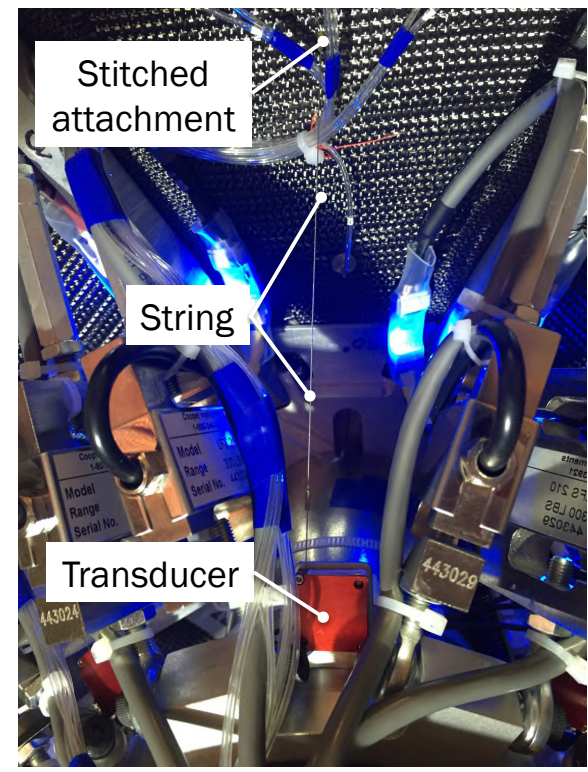

Figure 10. String potentiometer installed on fabric test article.

The locations of the eight string potentiometers are shown below in the top image of Figure 11. The bottom image of Figure 11 is a section view of the fabric test article showing that the string potentiometers are all attached to the central ring. This central ring translates (up or down as indicated by the blue arrows) in order to increase and decrease fabric tension by causing the ribs to move outward by a fraction of a degree. The eight string potentiometers are attached to the central ring, and so they also move slightly as the tension setting is changed. 

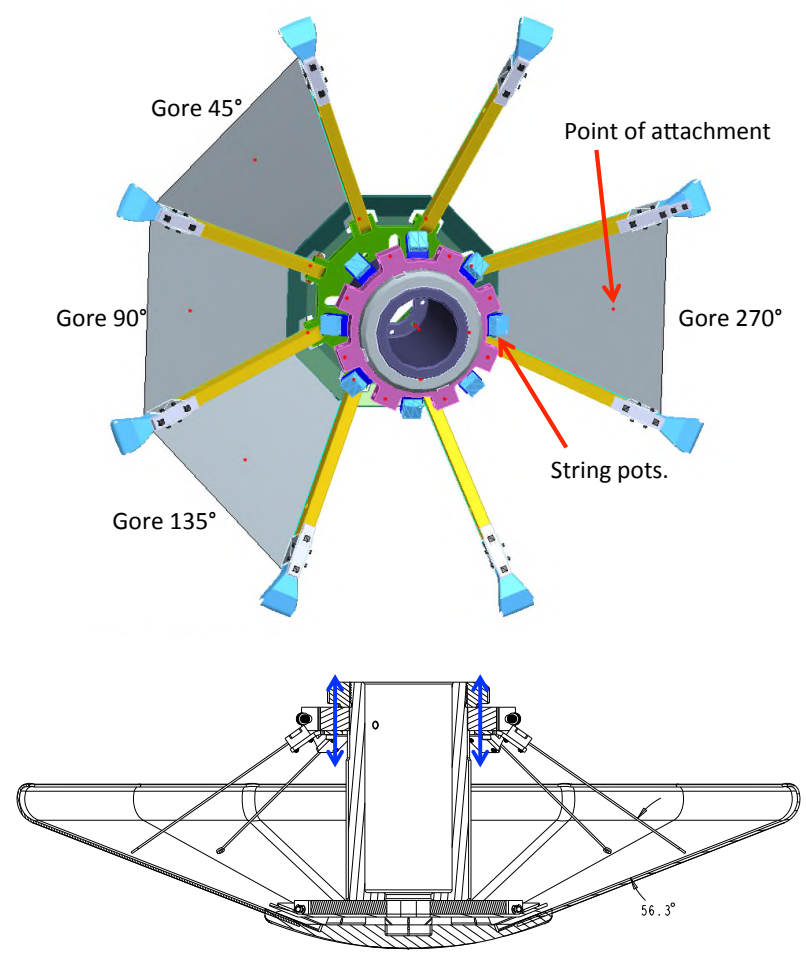

Figure 11. String potentiometer locations (top) and attachment at moving ring showing translation with different tension settings (bottom).

Strut Loadcells-An in-line S-beam style loadcell was used on each of the 16 struts in order to measure the load distribution in the fabric test article. Figure 12 shows a drawing of the strut load cells used for this test. These load cells have a range of 0 $300 \mathrm{lbs}$ and an accuracy of $\pm 0.2 \mathrm{lbs}$. Custom in-line amplifiers were fabricated in order to mitigate signal noise and degradation over the long leads back to the data system. The loadcell calibrations were checked before integration into the fabric test article by comparing the output when a known force was applied through a load frame over the full range of the sensor
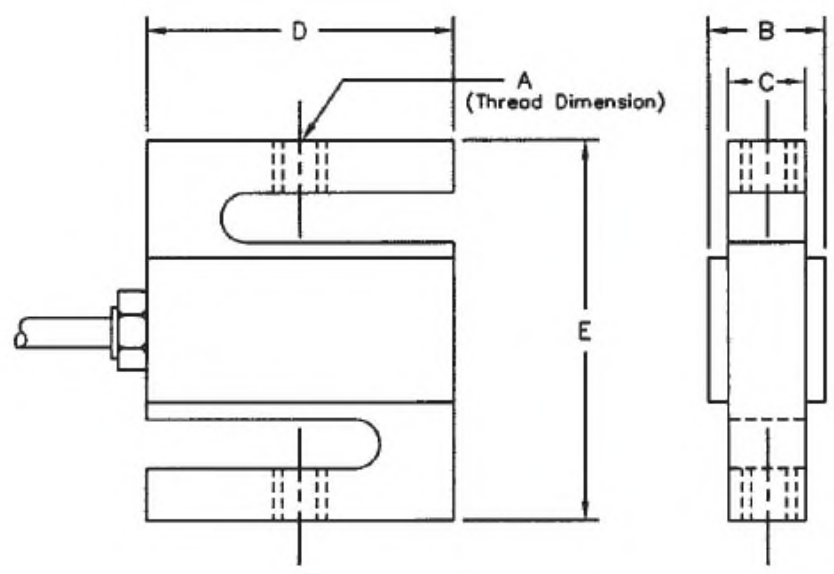

Figure 12. Load cells installed on each of the 16 struts of the fabric test article.
Pressure Taps-To anchor CFD modeling, custom surface pressure ports were fabricated and integrated with the carbon fabric. A total of 31 pressure taps were integrated into the carbon fabric of the fabric test article. An additional five pressure ports were integrated into the rigid nose of the fabric test article. Figure 13 shows the relative size of a pressure tap and how it is integrated into the carbon fabric. The port is carefully inserted in between carbon fabric tows in order to not damage the fibers. A brass back plate is then inserted onto the tube from the inner mold line (IML) side and secured in place with RTV. Pressure data were recorded by the 7x10 facility's Scanivalve system utilizing a \pm 1 psi pressure scanner. Pressure data are referenced to tunnel static pressure and reported as a non-dimensional pressure coefficient in this paper.

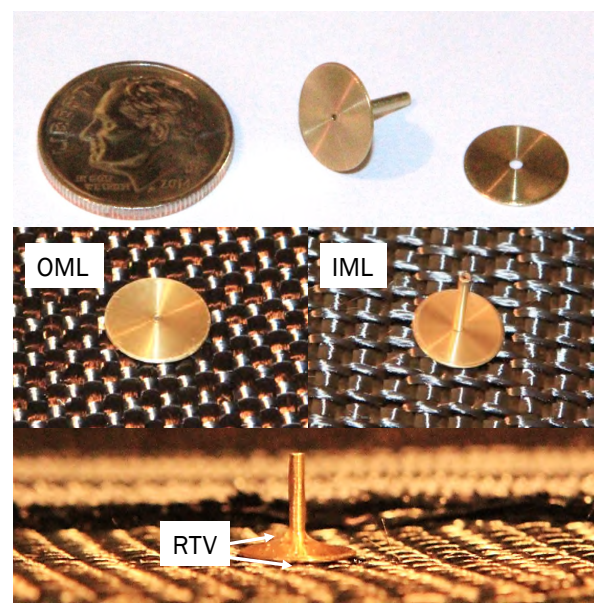

Figure 13. Brass pressure taps integrated with carbon fabric skirt.

High Speed Video-A high-speed camera was employed to image the trailing edge of the fabric skirt to determine if aeroelastic motion (flutter or buzzing) was occurring. A Photron SA1 camera, equipped with a $135 \mathrm{~mm}$ focal length lens was mounted onto a tripod resting on vibration damping pads $\left(1 / 2\right.$ inch thick Sorbothane $\left.{ }^{\circledR}\right)$. The camera was pointed from the north side of the tunnel, approximately 3 feet from the plexiglass windows lining the test section. A $750 \mathrm{~W}$ theater lamp mounted upstream was used to augment the ambient lighting in the tunnel during high-speed imaging to allow for sufficient depth of focus and contrast.

\section{Solid Test Article}

The solid test article copies the outer mold line (OML) geometry and surface texture of an infinite-tension fabric test article. Carbon fabric is glued to eight trapezoidal plastic parts that simulate the gores in order to mimic the surface roughness of the fabric test article. These plastic parts are supported by aluminum ribs. Figure 14 displays how the 3D-printed plastic pieces snap together with the aluminum ribs to form the shape. Additional fabric-covered plastic pieces cover the joints between gores and simulate the fabric seams. Figure 15 shows the complete sold test article installed in the $7 \times 10$ tunnel. The nose cap is identical to that used on the fabric test article. Clax was used to cover the nose cap bolt countersinks and to seal the gap between the nose cap and the ribs. 

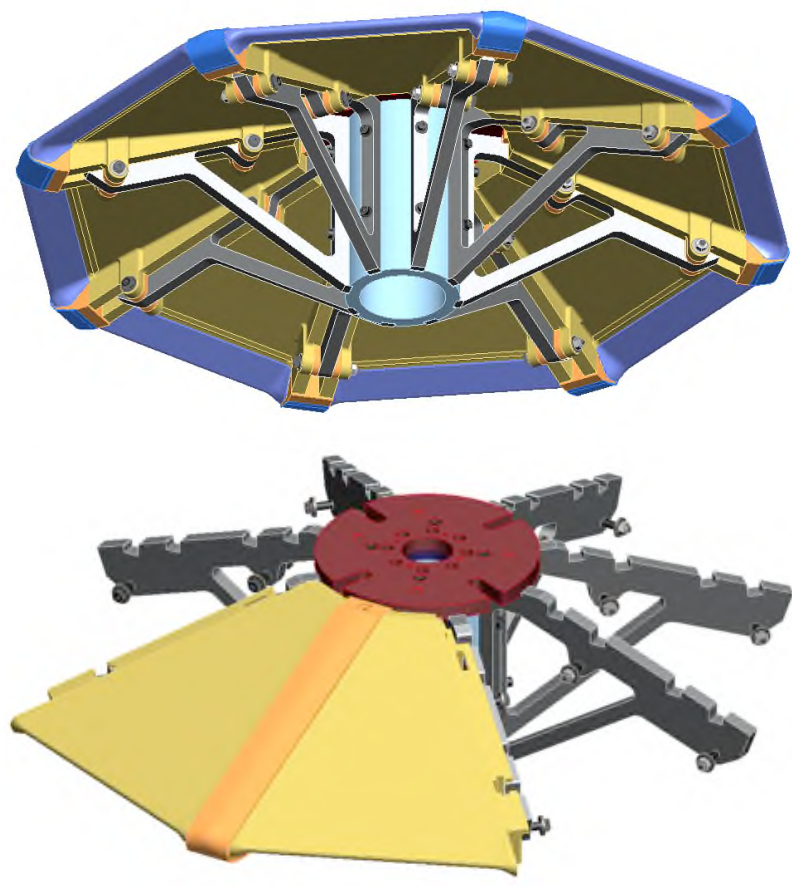

Figure 14. Solid test article aft view (top) and front view shown with missing panels (bottom).

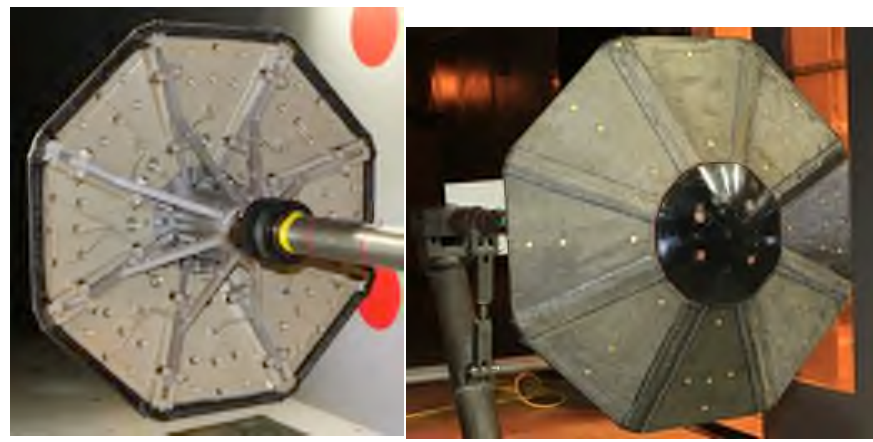

Figure 15. Solid test article rear view (left) and front view (right) installed in the $7 \times 10$ tunnel.

\section{Solid Test Article Instrumentation}

The solid test article was instrumented with pressure taps in the same pattern as the fabric test article in order to ease data comparison between the two test articles. The pressure taps were precisely located in the CAD based on the qualitative guidance in Figure 6. This allowed for the creation of a template that was printed on paper and used to locate the pressure taps on the fabric test article. An additional four pressure taps were added to the solid test article that were not included on the fabric test article to aid in CFD validation. Ribs R3 and R8 include two additional taps on the "peaks": one at the shoulder (P38, P40) and one at the nose cap (P37, P39).

\section{StATiC LoAdS AND DEFlections}

This section presents data supporting test objectives one and three. Information from all available data sources is used to discuss these observations. There is a great deal more data available in archive than is presented here. The intent here is to use representative data examples from the test to support specific observations. Topics discussed include evidence of fabric relaxation, shape memory, effect of pre-tension on deflection, effect of pre-tension on strut loads, effect of deflection on drag, effect of deflection on yaw moment, and deflection asymmetries.

The data reduction processes used for the strut load cells, string potentiometers, and photogrammetry are described in Appendix B. This section makes use of "radar" plots to display most of the string potentiometer and strut load cell data. This tool serves as an effective visual cue for quickly understanding qualitative trends. Surmising quantitative data from these plots will require reading Appendix B.

\section{Evidence of Fabric Relaxation}

There is evidence that the carbon fabric "relaxed" from its initial state during the course of the wind tunnel test. Fabric relaxation refers to the effect of individual fiber tows and stitches shifting around within the fiber matrix until they settle into a favorable location. Even though part of the manufacturing process involves conditioning the fabric until the load/deflection curve has no hysteresis, evidently the fabric relaxed sometime in the manufacturing or handling processes that took place between conditioning and the wind tunnel test. First indications of fabric relaxation came after the tension in the fabric was measured after the first two runs of the fabric test article. A significant drop in tension of $\sim 40 \%$ was noted. This observation is confirmed by other data sources. Data supporting this observation from the strut load cells were shown as an example of how to read the radar plots in this paper in Figure 35. Figure 16 shows the definition of a positive angle of attack used consistently in this report.

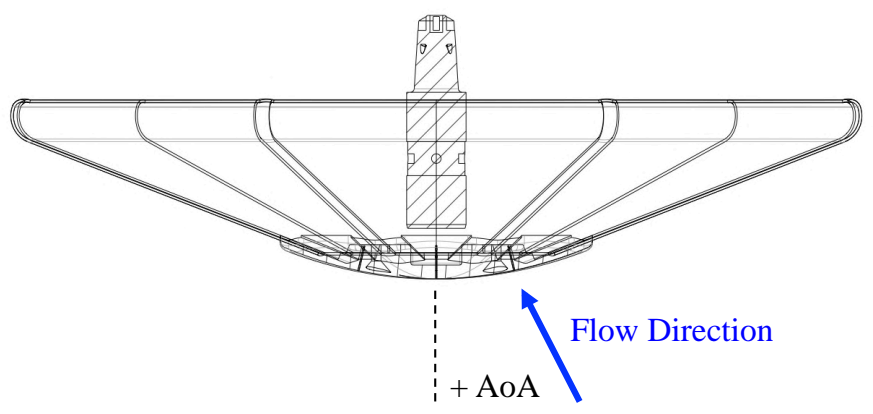

Figure 16. Definition of positive angle of attack.

String potentiometer data also shows evidence of fabric relaxation. This can be seen by comparing the string potentiometer values between chronological test points taken at the same test condition (nut setting, AoA, and Q). Data is displayed in Figure 17 at three angles of attack and $75 \mathrm{psf}$ dynamic pressure at the $20 \mathrm{lbf} / \mathrm{in}$ nut setting, which was the first to be tested. Figure 17 shows that deflection is increasing at the same test condition as more and more test points are taken. Test points taken later in the test matrix always tended to have greater deflection than previous test points taken at the same condition for this example. Measurements of fabric tension between runs using the tension measurement device show that this trend toward fabric relaxation tended to decrease as the week of testing went on. 

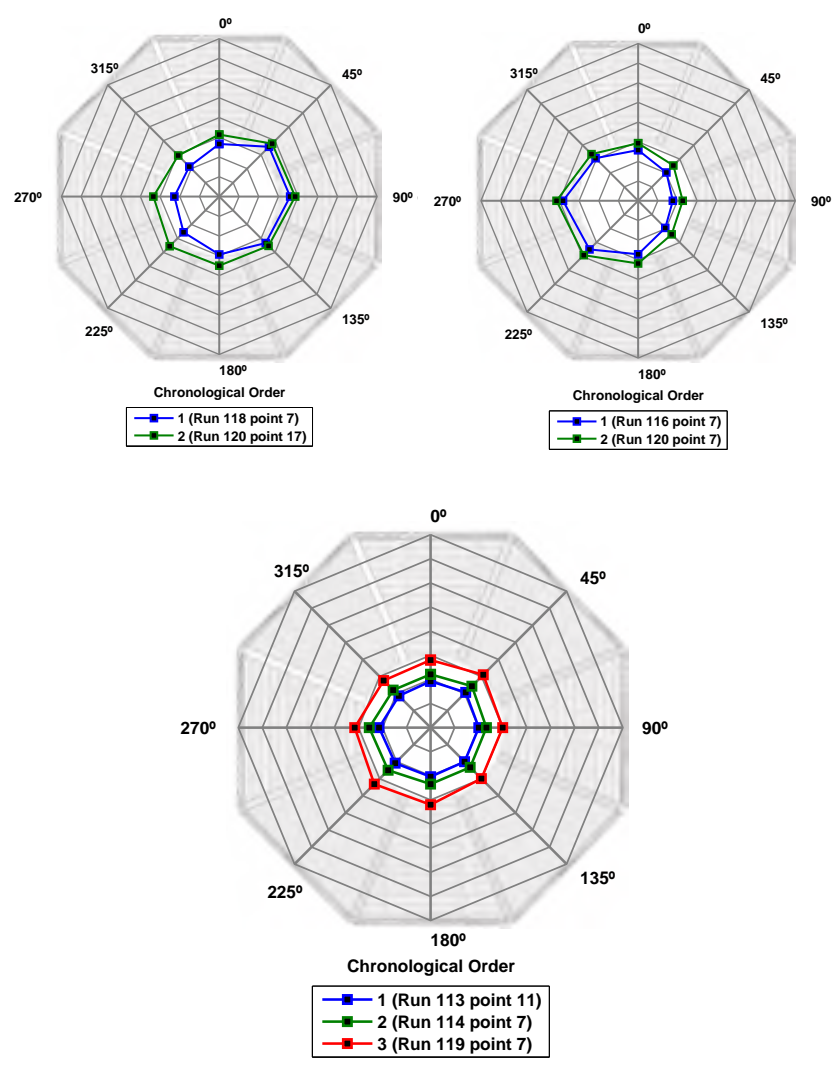

Figure 17. Effect of fabric relaxation. String displacement data for the $20 \mathrm{lbf} / \mathrm{in}$ nut setting at $75 \mathrm{psf}$ and $+20^{\circ} \mathrm{AoA}$ (top left), $0^{\circ}$ AoA (bottom) and $-20^{\circ}$ AoA (top right). Zero Strategy 3 was used. Isoline $=\mathbf{0 . 0 2 5}$ in. Center of figure $=0$ in.

\section{Load-Deformation Hysteresis}

The data show that the carbon fabric has a significant amount of hysteresis in its load-deformation behavior. A typical "run" in the wind tunnel involved increasing Q from 0 psf to $100 \mathrm{psf}$ then reducing $\mathrm{Q}$ back to 0 psf. While inspecting the fabric test article after a given run, it was observed that the fabric tended to retain a deflected state. The fabric in some cases was manually shifted back to a flatter state. The amount of deflection retention was greater at the lower pre-tension levels than higher pre-tension levels. Figure 18 shows string potentiometer data at three angles of attack and 75 psf dynamic pressure at the $20 \mathrm{lbf} /$ in measured tension setting. This was the highest tension state tested in this test campaign. Displayed on the three figures are two chronological test points, one taken before and one taken after the peak Q of 100 psf was reached. The figures show that the second instance of this identical test condition had greater deflection. This data shows that the loaddeformation hysteresis causes the fabric to maintain some of its shape when dynamic pressure is reduced.
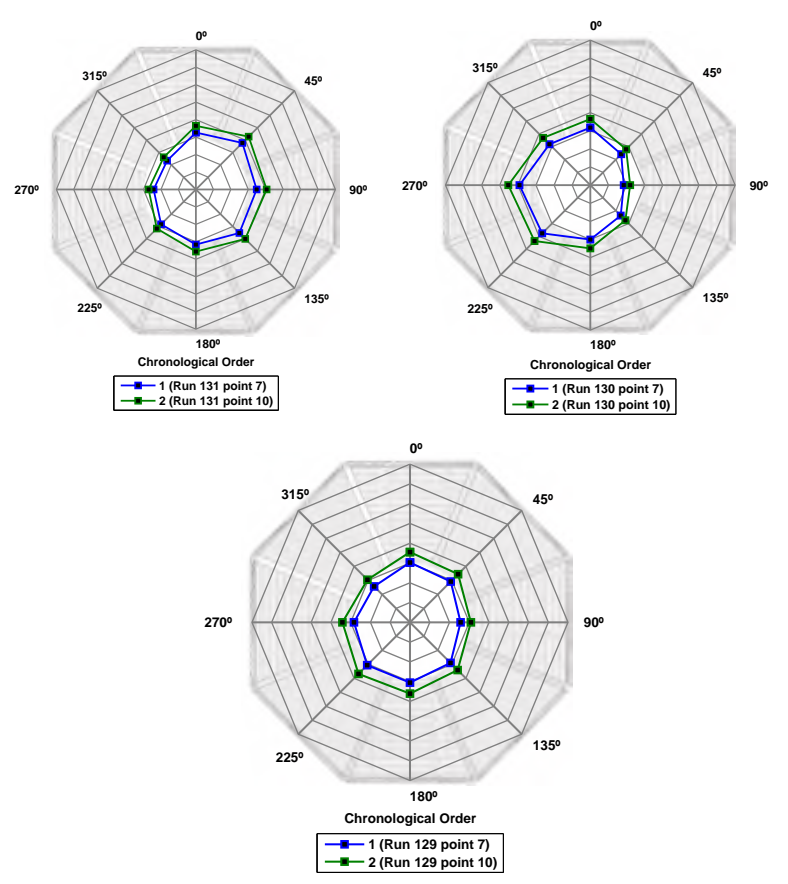

Figure 18. Effect of shape memory. String displacement data for the $20 \mathrm{lbf} / \mathrm{in}$ measured setting at $75 \mathrm{psf}$ and $+20^{\circ}$ AoA (top left), $0^{\circ}$ AoA (bottom) and $-20^{\circ}$ AoA (top right). Zero Strategy 3 was used. Isoline $=\mathbf{0 . 0 2 5}$ in. Center of figure $=0$ in.

The hysteresis of the woven carbon fabric may be important to consider for design reference missions that maintain some portion of flight at angle of attack prior to returning to ballistic flight. In Figure 19, additional string potentiometer data from a run taken as part of an angle-of-attack sweep (Run 120 point 13) has been added to the plot already shown in Figure 17. In this run the test article was held at 75 psf and swept from $-20^{\circ}$ AoA to $+20^{\circ}$ AoA in increments of $5^{\circ}$. It appears that some of the shape deformation imparted into the fabric when the test article was at negative angles of attack is still present in the fabric when the test article is at $0^{\circ}$ AoA. In flight this could cause the vehicle to maintain some small amount of trim due to asymmetric load. The impact of these observations needs to be evaluated for a given DRM.

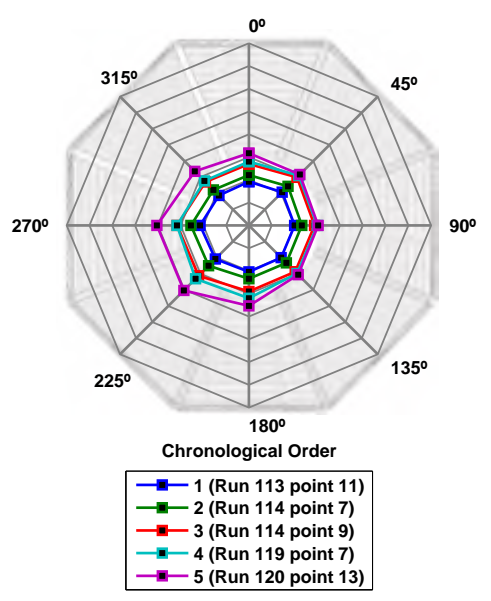

Figure 19. Evidence of shape memory (Zero Strategy 3). Isoline $=\mathbf{0 . 0 2 5} \mathrm{in}$. Center of figure $=0 \mathrm{in}$. 


\section{Effect of Pre-Tension on Deflection}

Fabric deflection calculations from photogrammetry data are shown in Figure 20. Deflections for a representative run from each tension setting for the three gores visible to the photogrammetry system are shown. The legend is the same for each of the three charts and moves downward in order of increasing fabric pre-tension (note that this is not the chronological order of testing). The horizontal axis is the target dynamic pressure for that test point. With the exception of the $100 \mathrm{psf}$ condition, the wind tunnel operators were generally able to achieve the target dynamic pressure with good accuracy (+/- 0.5 psf) as measured by the wind tunnel pitot probe. Of the runs shown, only in Run 119 was the tunnel not able to achieve $100 \mathrm{psf}$ (98.9 psf was achieved). The vertical axis is the deflection calculated using the technique depicted in Figure 37 at the string potentiometer anchor locations. A subset of test points was selected for deflection calculation due to the time consuming and manual nature of the data analysis process. Calculations were performed at 10 psf, $75 \mathrm{psf}$, and $100 \mathrm{psf}$ in order to resolve an overall trend for a given run. Two additional test points were processed for the $5 \mathrm{lbf} / \mathrm{in}$ case at $20 \mathrm{psf}$ and $50 \mathrm{psf}$ to better resolve the gradient at low dynamic pressures. The trend lines are forced to pass through the origin $(0 \mathrm{psf}, 0$ in.) since photogrammetry zeros were not taken for every run.

The photogrammetry data shows that the deflection decreases as pre-tension is increased above the $5 \mathrm{lbf} /$ in nut setting. At this nut setting the fabric was essentially slack and could easily be manipulated by hand. The small drop in deflection in the $90^{\circ}$ gore from $10 \mathrm{psf}$ to $20 \mathrm{psf}$ of the $5 \mathrm{lbf} /$ in nut setting is most likely a non-physical artifact of the data reduction process. The three runs shown at the $20 \mathrm{lbf} / \mathrm{in}$ nut setting and the one run at the $20 \mathrm{lbf} /$ in measured setting all show similar deflections.

Sensitivity of deflection to pre-tension can be seen in Figure 21 , which shows string potentiometer displacement data for all eight struts plotted versus the estimated pre-tension. The horizontal axis is estimated pre-tension from measurements made in the wind tunnel using the technique described earlier in this paper. The vertical axis is the raw string potentiometer values zeroed using Zero Strategy 1 to give a string displacement. String displacement can be thought of as a proxy for gore deflection, although the two are not equivalent due to geometric nuances (e.g. string is not perpendicular to the gore; string potentiometer transducers are mounted to the moving ring so there are small changes in string length as the central nut is rotated to change pre-tension). The data show a trend of decreasing total deflection and decreasing deflection variation with increasing pre-tension. Both of these trends agree qualitatively with the photogrammetry data shown in Figure 20. Additionally, it can be seen that the deflection variation between the $20 \mathrm{lbf} / \mathrm{in}$ cases decreases with increasing dynamic pressure.
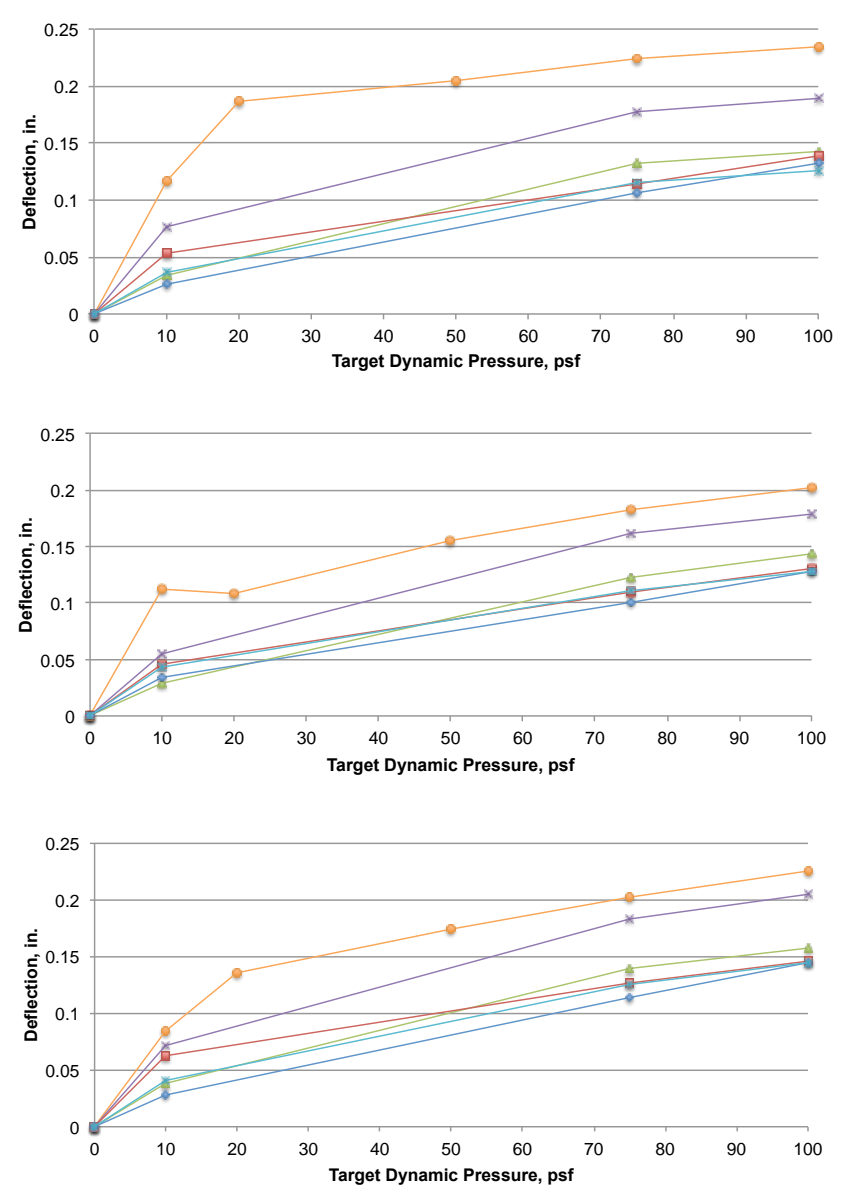

$-5 \mathrm{lbf} /$ in nut setting (Run 132) $-* 10 \mathrm{lbf} /$ in nut setting (Run 122) $-4-20 \mathrm{lbf} /$ /in nut setting (Run 119) $\rightarrow-20 \mathrm{lbf} /$ in nut setting (Run 114) $\rightarrow-20 \mathrm{lbf} /$ in nut setting (Run 113) $\rightarrow-20 \mathrm{lbff} /$ in measured (Run 129)

Figure 20. Deflection calculations from photogrammetry for $45^{\circ}$ (top), $90^{\circ}$ (center), and $\mathbf{1 3 5}^{\circ}$ (bottom) gores.

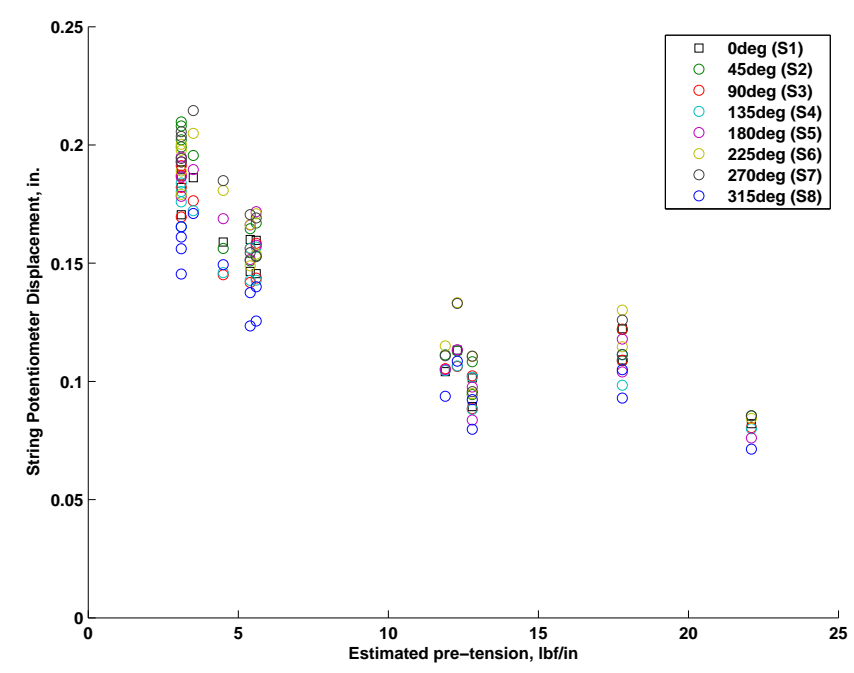

Figure 21. String potentiometer values for test points at $0^{\circ}$ AoA and 75 psf dynamic pressure. Zero Strategy 1 was used.

It is noted that due to the geometry of the fabric gores and the pivot locations of the supporting ribs, the tension in each gore 
may vary radially - especially as the rib angles are adjusted to off-nominal settings. The fabric test article was designed to have equal fabric tension loading as the model radius varies (inboard to outboard) for a nominal rib angle of $69.5^{\circ}$. As the deployed rib angles are reduced to reduce tension in the fabric, the tension drops off more quickly in the outboard regions of the fabric than the inboard regions. Cross-sections of the $90^{\circ}$ gore deflected shape were taken from the photogrammetry data. The effect of reduced outboard tension is observed in Figure 23 as it can be seen that the point of maximum deflection (PNT4) has moved outboard in comparison to the point of maximum deflection for the high tension run condition shown in Figure 22.

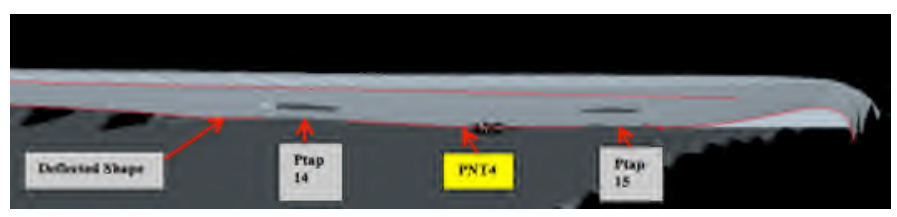

Figure 22. Cross section of $90^{\circ}$ gore: $20 \mathrm{lbf} / \mathrm{in}$ measured tension, 100 psf and $0^{\circ}$ AoA.

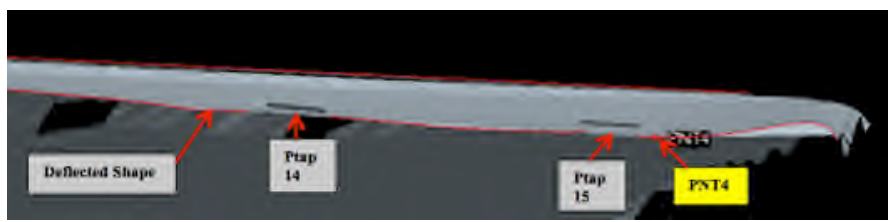

Figure 23. Cross section of $90^{\circ}$ gore: 5 lbf/in nut setting, 100 psf and $0^{\circ}$ AoA.

In flight, the allowable total deflection as well as allowable deflection uncertainty will drive the pre-tension design choice. This requirement will be driven by aerothermodynamic and aerodynamic requirements (trending toward higher pretension) with mass tradeoffs driven by structures and mechanisms requirements (trending toward lower pre-tension). Ultimately a trade study must be performed specific to a given mission in order to make the best selection. However, it is possible to get a high-level idea of how the deflections measured in this test compare with DRM requirements. As part of an earlier effort, a study was conducted to assess the feasibility of using a $6 \mathrm{~m}$ diameter ADEPT to deliver a $\sim 1000$ $\mathrm{kg}$ payload to the surface of Venus [3]. In that study a soft requirement was levied on fabric deflection in order to minimize local heating augmentation just inboard of the trailing edge shoulder due to flow re-attachment. The requirement was that the deflection, $\delta$, shall not exceed $1.5 \%$ the flow-wise running length of the gore, $L$ (or $\delta / \mathrm{L} \leq 0.015$ ). This " $\delta /$ L requirement" was driven by a constraint on the peak heat rates not exceeding tested limits of the carbon fabric of $\sim 250 \mathrm{~W} / \mathrm{cm}^{2}$. For DRMs with lower peak heat rates this $\delta / \mathrm{L}$ limit could be relaxed significantly. Using the same $\delta / \mathrm{L}$ limit from this study, the deflection limit for the $0.7 \mathrm{~m}$ diameter Nano-ADEPT of this test would be 0.128 in. ( $\mathrm{L}=8.5 \mathrm{in}$.). The deflections measured at the higher tension settings of this wind tunnel test are in the neighborhood of this limit.

\section{Effect of Pre-Tension on Strut Loads}

Increasing fabric pre-tension causes the loads in the struts to increase. This effect can be seen in Figure 24, which compares strut loads for dynamic pressure sweeps at four different tension settings. The strut loads start from a higher value when the pre-tension is higher. In the example below, struts at the 20 lbf/in nut setting have about $40 \mathrm{lbf}$ of compression force each at a low 20 psf dynamic pressure. Compare this to the $5 \mathrm{lbf} / \mathrm{in}$ nut setting at the same dynamic pressure where each strut has about $20 \mathrm{lbf}$ of compression force. Because the fabric was essentially slack the $5 \mathrm{lbf} /$ in nut setting, it is safe to attribute nearly all of the load in the struts to dynamic pressure effects. The strut load data at higher tension settings shows how the structure carries the added load from the fabric pre-tension.

Changing the angle of attack also has an impact on strut loads. Figure 25 compares strut loads at two different angles of attack and the four pre-tension settings. All of this data is at the same dynamic pressure of 90 psf. This example shows that the strut loads increase as the gore becomes more perpendicular to the flow. Conversely, strut loads tend to decrease when the gore is more parallel to the flow. Despite asymmetries in gore deflection, the distribution of loads within the struts is uniform and predictable.
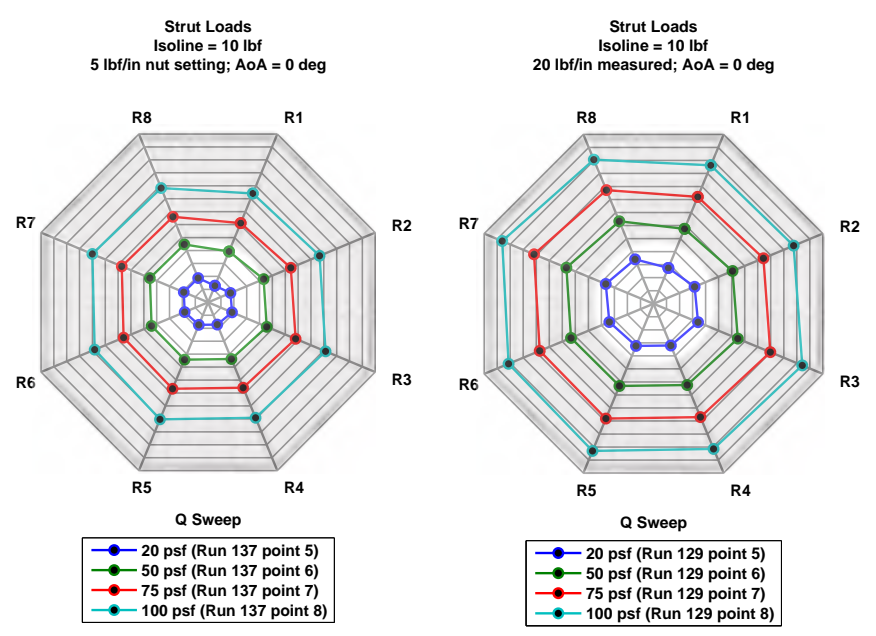

Figure 24. Effect of pre-tension on strut loads: $\mathbf{Q}$ sweeps at a low (left) and high (right) tension setting. Isoline $=10 \mathrm{lbf}$. Center of figure $=0 \mathrm{lbf}$. 


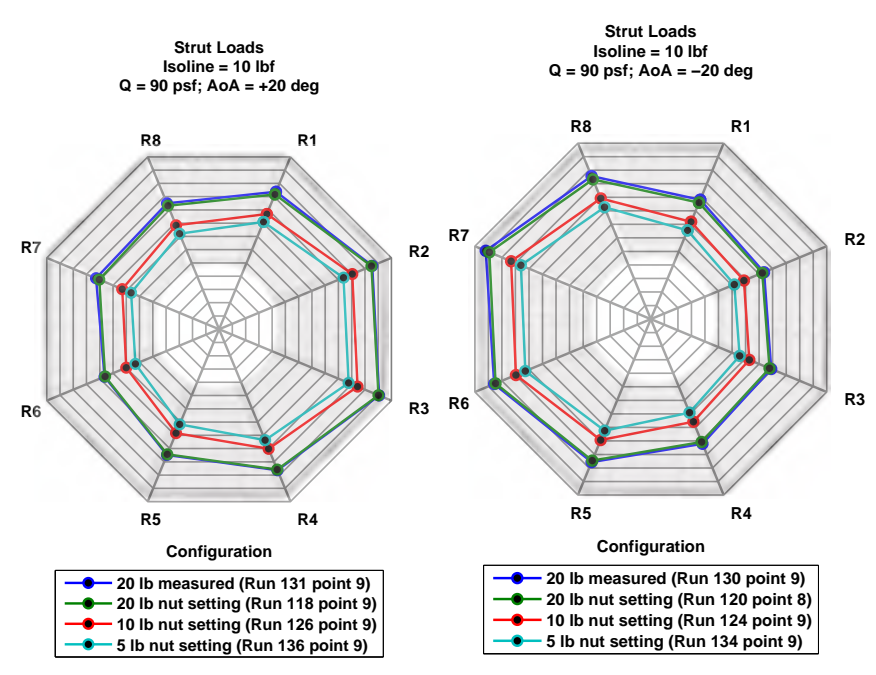

Figure 25. Effect of pre-tension on strut loads: Four tension settings at $+20^{\circ} \mathrm{AoA}$ (left) and $-20^{\circ} \mathrm{AoA}$ (right). Isoline $=10$ lbf. Center of figure $=0$ lbf.

\section{Effect of Deflection on Drag}

Fabric deflection has the potential to change aerodynamic drag (axial force). Although hypersonic speeds are the primary interest, the internal balance data from this test allow us to compare axial force coefficient at subsonic speeds. Axial force coefficient, $C_{A}$, is defined as

$$
C_{A}=\frac{F_{A}}{q_{\infty} S_{r e f}}
$$

where $\mathrm{F}_{\mathrm{A}}$ is the axial force measured by the internal balance, $q_{\infty}$ is the freestream dynamic pressure, and $S_{r e f}$ is the reference area. For simplicity purposes, $S_{r e f}$ is defined as the area of a circle of $0.7 \mathrm{~m}$ diameter:

$$
S_{\text {ref }}=\frac{\pi\left(D_{\text {ref }}\right)^{2}}{4}=0.3848 \mathrm{~m}^{2}=4.1424 \mathrm{in}^{2}
$$

Axial force coefficient at $0^{\circ}$ AoA is displayed in Figure 26 as a function of pre-tension and dynamic pressure. Pre-tension estimates are those taken with the tension measurement tool after some of the runs. If a tension measurement was not made for a particular run, the tension measurement from the previous run at the same tension setting was used. These figures show all axial force coefficient data for the runs at $0^{\circ} \mathrm{AoA}$ and so multiple pre-tensions and dynamic pressures are being shown. Data from the solid test article are displayed on the axial force coefficient versus dynamic pressure plot. These data suggest that axial force coefficient is mostly independent of pretension and dynamic pressure at these speeds. Given that the flow is incompressible, the observation that $\mathrm{C}_{\mathrm{A}}$ is independent of dynamic pressure is consistent with theory. The $\mathrm{C}_{\mathrm{A}}$ data show a weak dependence on pre-tension, increasing by a few percent as pre-tension is increased to $10 \mathrm{lbf} / \mathrm{in}$ and then remains relatively constant. The dependence of $\mathrm{C}_{\mathrm{A}}$ on pretension would likely be more pronounced in hypersonic flow where Newtonian flow theory suggests surface perpendicularity drives the axial component of force.
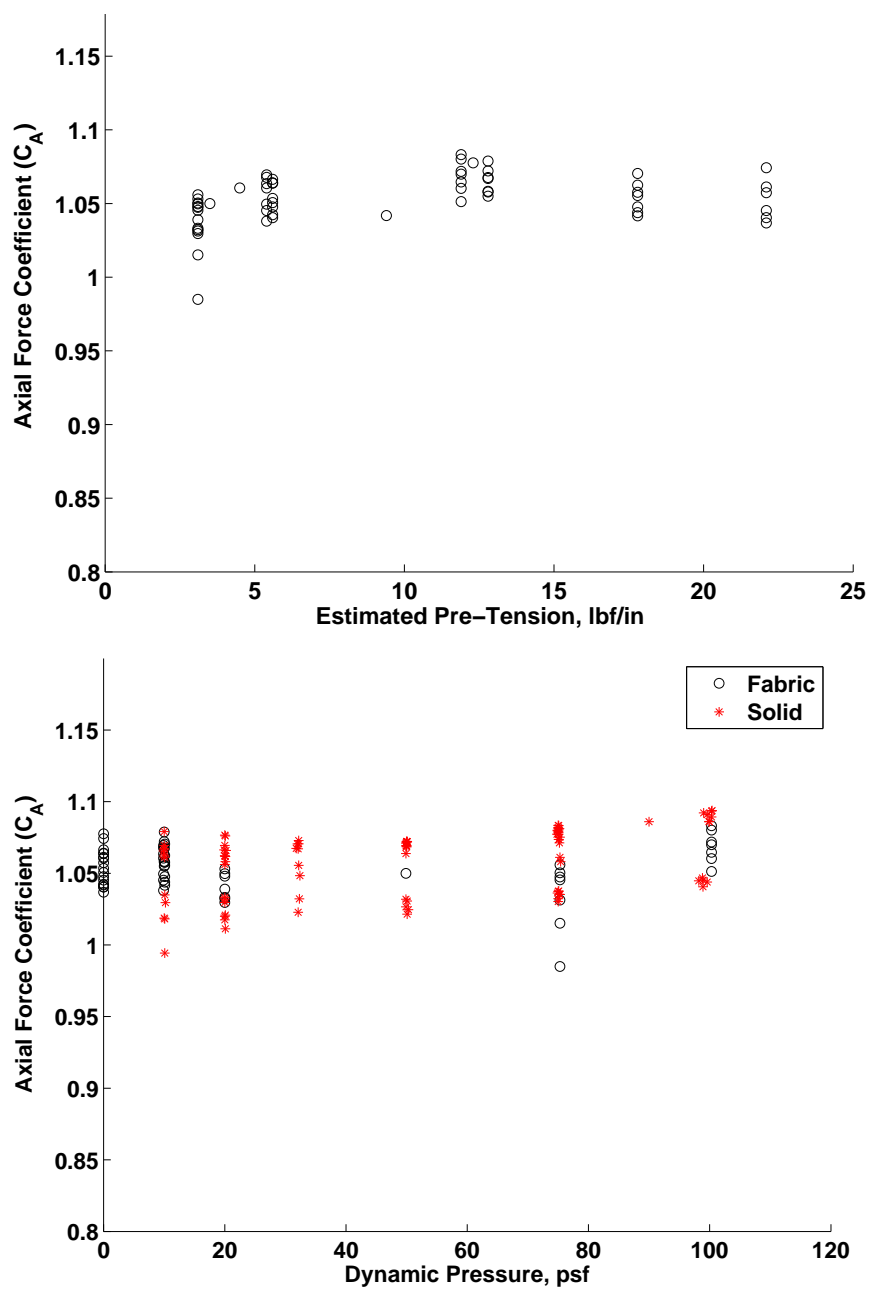

Figure 26. Axial force coefficient at $0^{\circ} \mathbf{A o A}$ versus estimated pre-tension (top- all $Q$ shown) and dynamic pressure (bottom- all pre-tensions shown incl. solid test article).

During testing the question was raised if the small projected area change resulting from changing pre-tension could contribute to any difference in drag between the different tension settings. The projected area at different tension settings is displayed below in Table 5. These values were calculated using the CAD model of the fabric test article. Rib angles were modeled per the actual measurements for each case. The area change as a result of adjusting pre-tension is less than $1 \%$ and so is unlikely to affect the drag in any significant way.

Table 5. Projected area comparison of fabric test article at different tension nut settings compared to an ideal shape.

\begin{tabular}{|c|c|c|}
\hline Setting & $\begin{array}{c}\text { Projected } \\
\text { Areas }\left(i^{2}\right)\end{array}$ & $\begin{array}{c}\% \text { of ideal } 70^{\circ} 8- \\
\text { sided pyramid }\end{array}$ \\
\hline \hline Ideal & 552.51 & $100 \%$ \\
\hline $20 \mathrm{lbf} /$ in nut setting & 551.35 & $99.8 \%$ \\
\hline $10 \mathrm{lbf} /$ in nut setting & 549.69 & $99.5 \%$ \\
\hline $5 \mathrm{lbf} /$ in nut setting & 548.14 & $99.2 \%$ \\
\hline
\end{tabular}




\section{Effect of Deflection on Yaw Moment}

Besides axial force, yaw moment was the only other load with significant magnitude measured by the internal balance. A yaw moment coefficient about the balance center is calculated as:

$$
C_{M \text { yaw balance }}=\frac{M_{\text {yaw }}}{q_{\infty} S_{\text {ref }} l_{\text {ref }}}
$$

where $l_{\text {ref }}$ is defined as $0.7 \mathrm{~m}$. Yaw moment coefficient as a function of angle of attack (yaw angle) is plotted in Figure 27. The data show a negative slope with increasing angle of attack, indicating static stability. There are no strong differences in yaw moment coefficient between the solid model and the different tension settings of the fabric test article, although the solid model does have a slightly stronger restoring moment at the higher angles of attack.

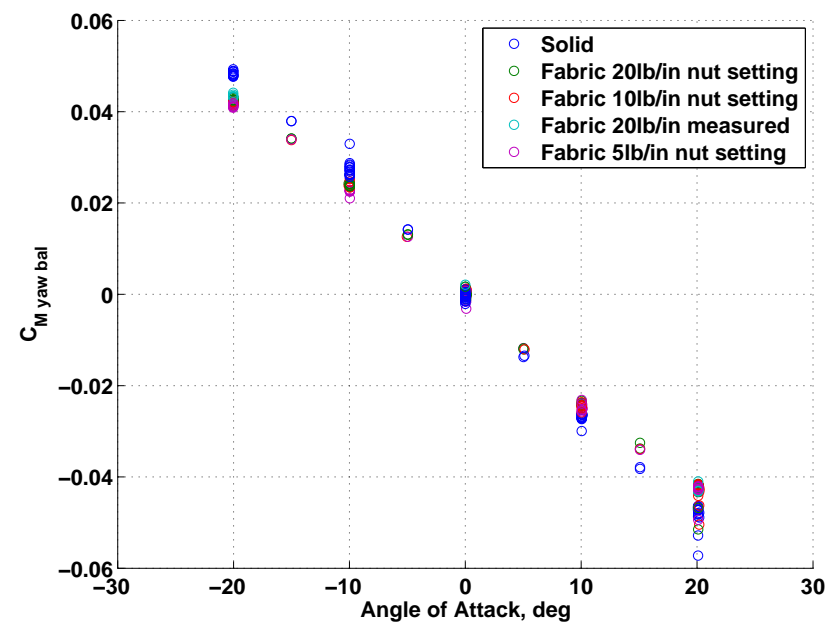

Figure 27. Yaw moment coefficient versus angle of attack for multiple tension settings.

\section{Deflection Asymmetries}

A typical photogrammetry data set is shown in Figure 28. This color map is showing displacement in the axial direction (into the page). Note that the nosecap and ribs are not at zero displacement in this color map. As mentioned earlier, only data from the $45^{\circ}, 90^{\circ}$, and $135^{\circ}$ gores is of usable quality. This figure shows that there is some asymmetry in the amount of deflection experienced by the different gores. There are also some asymmetries resulting from the inclusion of the pressure ports in the fabric. This can be seen in the cross section plots shown earlier in Figure 22 and Figure 23. A bulge can be seen in cross section at the locations of the pressure ports resulting from the added stiffness in those areas. In general, asymmetries in fabric deflection are most likely attributed to small asymmetries arising from manufacturing and assembly, such as carbon tow layout, stitching features, or interface with the rigid skeleton. A very small asymmetry in these parameters can impact the deflection symmetry on the scales observed in this test ( $\sim 0.10$ in. in example below comparing $45^{\circ}$ and $135^{\circ}$ gores). This effect will augment aerothermal heating environments as well as add uncertainty in aerodynamic coefficients.

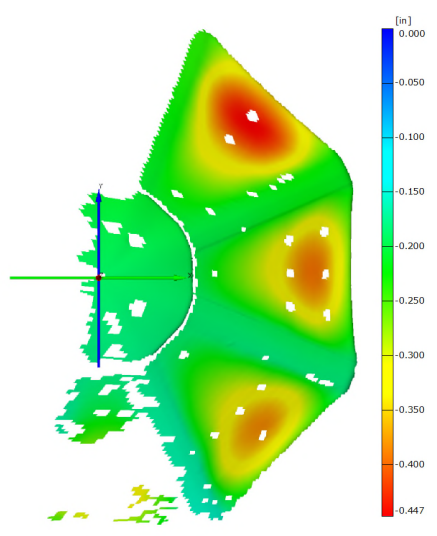

Figure 28. Typical photogrammetry solution (Run 119: 20 lbf/in nut setting, $0^{\circ} \mathrm{AoA}, 100 \mathrm{psf}$, actual tension $\sim 12$ Ibf/in).

\section{Static Loads and Deflection Summary}

The test data confirm that fabric pre-tension is a driving design parameter in the structural performance of Nano-ADEPT. Higher pre-tension tends to result in less deflection as well as less deflection variation. The wind tunnel data support adopting a pre-tension lower bound of $10 \mathrm{lbf} / \mathrm{in}$ for NanoADEPT mission applications. This pre-tension value corresponds to a knee in the load/deflection curve and seems to be a breaking point where deflection magnitude and variation change quickly. Adopting a pre-tension of at least $10 \mathrm{lbf} / \mathrm{in}$ will go a long way toward reducing static deflection, variation in drag coefficient and pressure distribution, and augmented aerodynamic heating. Note that achieving $10 \mathrm{lbf} /$ in of pretension will require designing the structure to achieve higher than $10 \mathrm{lbf} /$ in pre-tension to combat the fabric relaxation effects described in this section.

Determining how much pre-tension is required is a missionspecific question. Missions using Nano-ADEPT should consider additional wind tunnel testing at conditions tailored to the specific conditions of interest (e.g. test at peak dynamic pressure in the wind tunnel and perform aerothermodynamic heating analysis on the deflected shape). A ballistic flight without concern for trajectory accuracy can likely get by with pre-tension levels near those explored in this test. However, a mission requiring active control and precision landing may require higher pre-tensions and thus higher component loads to maintain shape. Alternatively, some amount of the aerodynamic uncertainty can be made up with a robust closedloop guidance and control algorithm. Ultimately the best choice of pre-tension must be made through a trade study for a specific mission.

\section{DYNAMIC FLUID STRUCTURE INTERACTION}

High-speed imagery was captured at 500 frames per second (fps), for 0.5 seconds upon reaching the desired test condition. Since the fabric skirt was patterned for photogrammetry, points at or near the trailing edge could be tracked to determine if there was flutter occurring. As a control experiment, data was collected on the solid test article as well to compare/contrast any observed movement behavior. 
High-speed imagery data was played back at slow frame rate $(\sim 30 \mathrm{fps})$ to visually observe overall behavior of the test articles. Playback of the solid test article imagery revealed that there was some rigid body movement of the entire test article. Slight non-uniformities in the flow field, tunnel vibrations and flexibility in the model support were noted as causes of rigid body movement. Playback of imagery acquired on the fabric test article revealed the same rigid body movement behavior as was observed in the solid test article. Figure 29 (left) shows a still image from the high speed imagery acquired at a tunnel condition of $100 \mathrm{psf},-10^{\circ} \mathrm{AoA}$. The test article was in a slack tension state, which was anticipated as being the most likely tension setting that any dynamic flutter would be observed. However, no dynamic flutter was observed. Figure 29 (right) shows a still image from the $90^{\circ}$ gore ( 3 o'clock) when the test article was adjusted into the asymmetric configuration, at a tunnel condition of $100 \mathrm{psf}$ and $+20^{\circ}$ AoA. Again, no dynamic flutter was observed. As a control, the non-patterned gore was also imaged at $100 \mathrm{psf}$ to confirm that additional stiffness imparted from the paint used for gore patterning was not obfuscating observation of flutter/buzz. No flutter/buzz of the fabric was observed for any test condition.

For the 6-layer fabric tested here, the bending stiffness of the trailing edge was sufficient to prevent structural oscillations induced by vortex shedding (flutter). The fabric in a flight case may have a different configuration with more or less carbon fabric layers. Furthermore, the fabric will pass through a heat pulse that could substantially change its mechanical properties. Layer loss, fiber graphitization, and fiber thinning due to oxidization are all mechanisms that could alter the mechanical response of the carbon fabric to an aerodynamic load. For these reasons a direct comparison is difficult between the room-temperature test environments and actual flight environments. However, it is possible to make some general conclusions on the meaning of the wind tunnel results applied to a flight environment by referring to basic principles of fluidstructure interaction. The lack of any observed fluttering of the free edges of the gores in this wind tunnel test likely eliminates that as a possibility for the intended flight conditions. The flow mechanism for fluttering is likely related to periodic vortex shedding from the body. Previous experiments have shown that the Strouhal number for blunt capsules is around 0.2 for subsonic free stream conditions. The shedding frequency is given by:

$$
f=\frac{S_{t} V}{D}
$$

where $S_{t}$ is the Strouhal number, $V$ is the velocity, and $D$ is the body diameter. At supersonic speeds the Strouhal number doubles to around 0.4 and the shedding is much less coherent [4]. Therefore the shedding frequency will increase by a factor of two times the ratio of the flight velocity to the wind-tunnel velocity. The free edges of the gores are not expected to have a natural frequency nearly as high as the shedding frequency, and so fluttering of the free edge should not happen in flight.

These arguments based on basic principals suggest that dynamic FSI will not occur in ADEPT flight environments. However, scaling the test observations to larger-scale designs requires further analysis and potentially testing at the component level to verify design codes with a fabric that more closely resembles the state and environment where FSI concerns exist. Verifying a flight design will require a more sophisticated physics-based analysis or appropriate missionspecific wind tunnel testing.
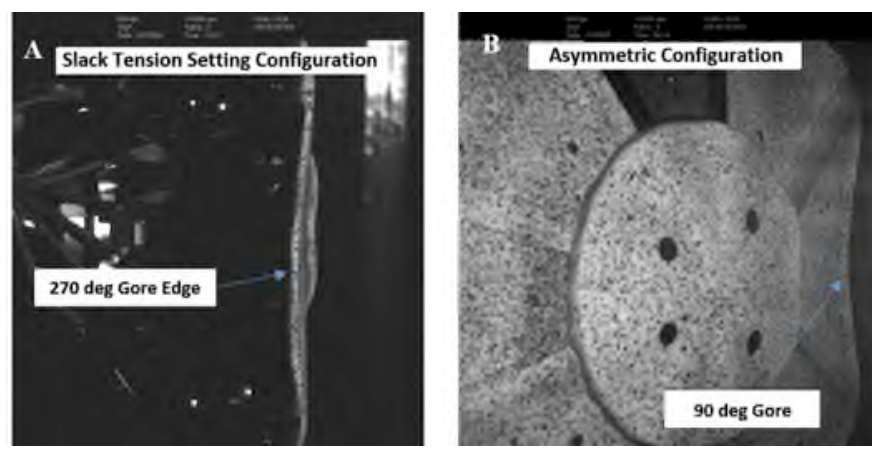

Figure 29. Still images from high speed imagery of slack tension setting at 100 psf and -10 degree $\mathrm{AoA}$ (left) and asymmetric configuration at $100 \mathrm{psf}$ and +20 degree $\mathrm{AoA}$ (right).

\section{ASYMMETRIC SHAPE}

An extra half-day of testing remained available after the nominal test matrix was complete. A decision was made to use the extra time to explore the effect of creating an asymmetric shape by shortening struts on one of the gores. The motivation for this experiment stems from mission concepts that wish to use the "adaptable" feature of ADEPT to form a lift-generating shape without the need for a center of gravity offset. This could be an enabling capability for missions requiring precision landing and/or aerocapture.

In order to create the asymmetric shape, two pairs of struts were shortened to give the $90^{\circ}$ gore ( 3 o'clock) a cone angle of $\sim 67^{\circ}$ (compared with $70^{\circ}$ for the rest of the gores). The central tensioning nut was set to the $20 \mathrm{lbf} /$ in nut setting so that data from the asymmetric shape could be compared with one of the tested geometries of the symmetric configuration. Figure 30 shows the asymmetric configuration and the angles of each of the ribs. The side view points out the two strut pairs that were shortened to create the shape.
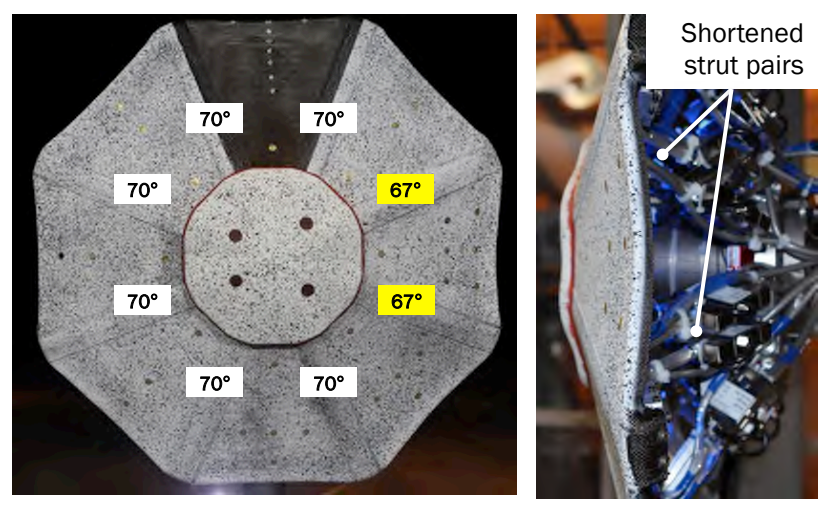

Figure 30. Asymmetric configuration front view (left) and side view (right). 
The capability of the asymmetric shape to generate lift is shown through the yaw moment coefficient data in Figure 31 below. The two data sets show that an offset in the zero-yaw angle of attack is created with the asymmetric shape. This offset suggests that the asymmetric configuration would trim at approximately $2.4^{\circ} \mathrm{AoA}$ in free flight.

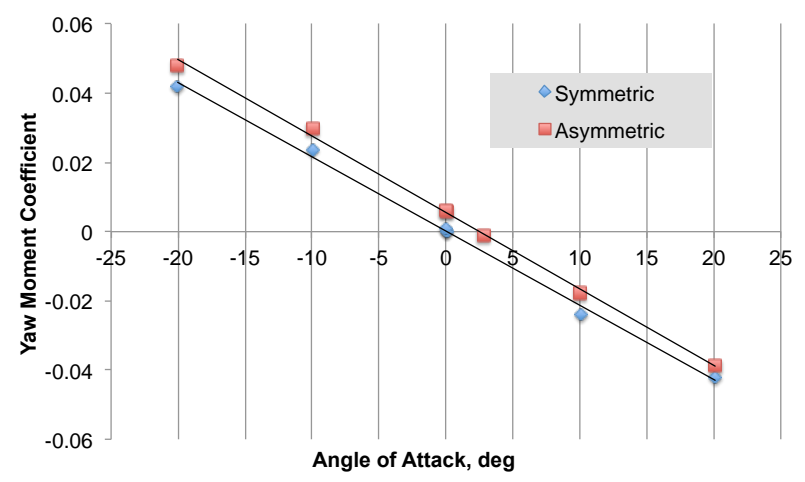

Figure 31. Yaw moment coefficient for symmetric and asymmetric configurations at the $20 \mathrm{lbf} / \mathrm{in}$ nut setting showing a trim angle of $\sim 2.4^{\circ}$.

Tension in the asymmetric configuration is lower than the symmetric configuration at the same geometric nut setting. Because the carbon fabric is one monolithic piece, the tension decreases uniformly throughout all gores even though only two of the strut pairs were shortened. This effect can be seen in the strut load data, presented in Figure 33. The figure compares strut load data for the symmetric and asymmetric configurations at three angles of attack. The asymmetry in the strut loads is evident in R2 and R3. Additionally, the average load in all of the struts has been reduced in the asymmetric configuration. Drag is also reduced in the asymmetric shape as is shown in Figure 32.

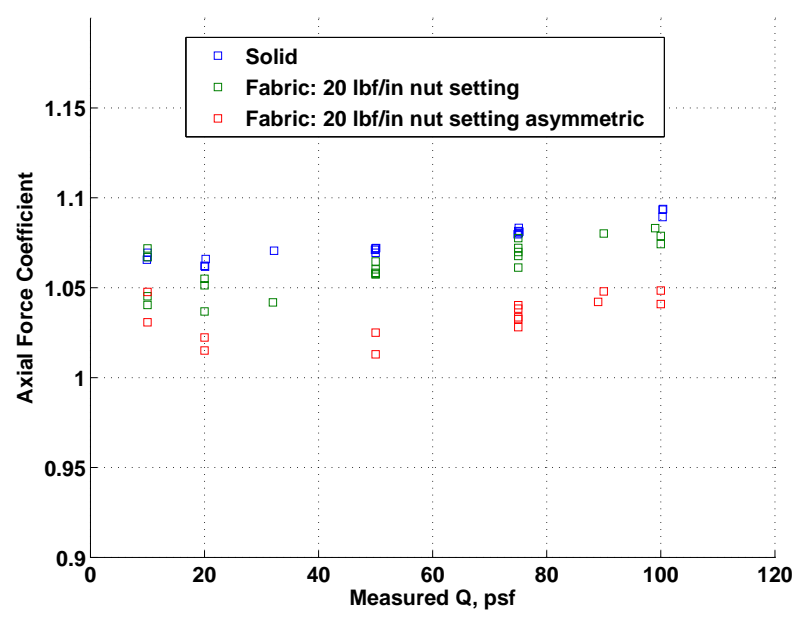

Figure 32. Axial force coefficient versus measured dynamic pressure for $20 \mathrm{lbf} / \mathrm{in}$ nut setting, symmetric and asymmetric configurations. All angles of attack are plotted.

These results have implications for a flight application of ADEPT that uses the adaptability of the aerosurface to generate lift. Doing so will also globally decrease tension and increase deflections as struts are actuated, which will change aerodynamic properties of the vehicle. Using ADEPT in this way will also require the use of a robust guidance and control algorithm that can make on-the-fly strut adjustments to correct the trajectory. With a strut actuation system and robust guidance and control algorithm, this effect could be used to steer a blunt body at hypersonic speeds to aid precision landing or aerocapture.
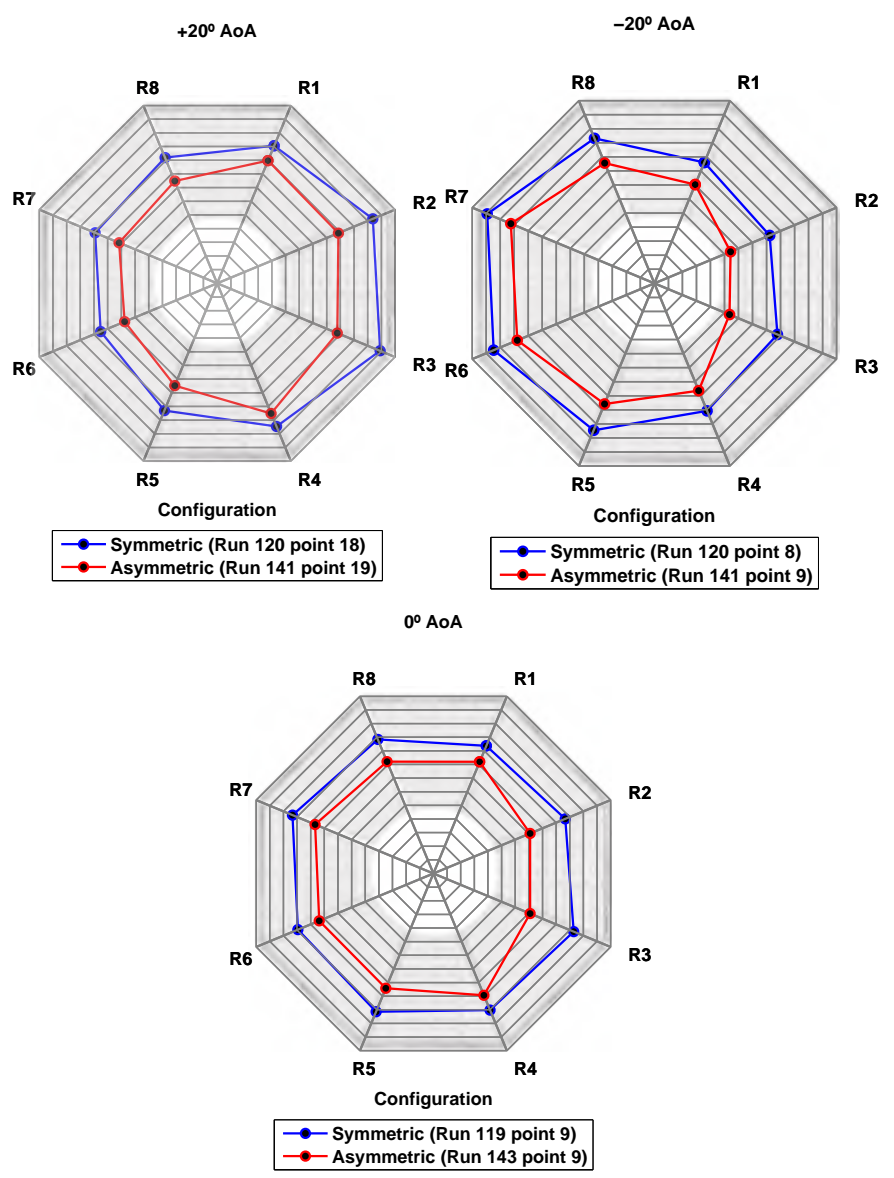

Figure 33. Strut load comparison of symmetric and asymmetric configurations at $20 \mathrm{lbf} /$ in nut setting at $+20^{\circ}$ (top left), $0^{\circ}$ (bottom), and $\mathbf{- 2 0}^{\circ}$ (top right) AoA. Isoline $=$ 10lbf. Center of figure $=0 \mathrm{lbf}$.

\section{Conclusions}

The Nano-ADEPT aeroloads wind tunnel test was successful. Wind tunnel data support adopting a pre-tension lower bound of $10 \mathrm{lbf} /$ in for Nano-ADEPT mission applications in order to minimize the impact of static deflection. Higher pre-tension will result in lower deflection, but there are diminishing returns as pre-tension is increased. Deciding the appropriate fabric pre-tension for a given mission ultimately requires a mission-specific trade study.

Test results indicate that the fabric conditioning process needs to be reevaluated. The first run of the fabric test article caused relaxation that resulted in $\sim 40 \%$ loss of pretension, indicating hysteresis in the load/deflection relationship of the carbon fabric. This implies that the fabric relaxed sometime in the manufacturing or handling processes that took place between conditioning and the wind tunnel test. Characterization testing is needed where the carbon fabric's load/deflection relationship is measured after having been stowed for a long 
duration. Solutions exist that are expected to mitigate the impact of fabric relaxation if an accurate load/deflection relationship cannot be predicted. For example, a worst-case static deflection could be defined based on characterization test data and the nominal pre-tension could be increased accordingly.

Prior to this test there was concern that the carbon fabric free edge could experience dynamic FSI ("buzz" or flutter) and cause a catastrophic structural failure. High-speed video was used in this test to capture any potential high-frequency gore movement. No flutter/buzz of the fabric was observed for any test condition and should also not occur at hypersonic speeds due to the natural frequency of the trailing edge being far lower than the flow shedding frequency.

Finally, reducing the cone half-angle of one gore from $70^{\circ}$ to $67^{\circ}$ caused the zero-yaw-moment angle of attack to offset by $2.4^{\circ}$. This experiment demonstrated the capability of ADEPT to generate aerodynamic lift without the need for a center of gravity offset. With a strut actuation system and robust guidance and control algorithm, this effect could be used to steer a blunt body at hypersonic speeds to aid precision landing or aerocapture.

\section{FUTURE WORK}

This wind tunnel test was one element of a larger technology maturation strategy for Nano-ADEPT. The Venn diagram in Figure 34 provides a high-level overview of this integrated approach [2]. Four test campaigns were designed to provide data that together will bring Nano-ADEPT to TRL 5. All of the technical elements within the subsonic aeroloads wind tunnel test section were addressed by this test. The majority of work remaining within this sector of the technology is within the FSI technical area. Specifically, a robust strategy is needed for selecting design parameters that affect the tension-state of the fabric in flight. Achieving this will require both FSI modeling improvements as well as novel design approaches that minimize the system-level impact of fabric behavior.

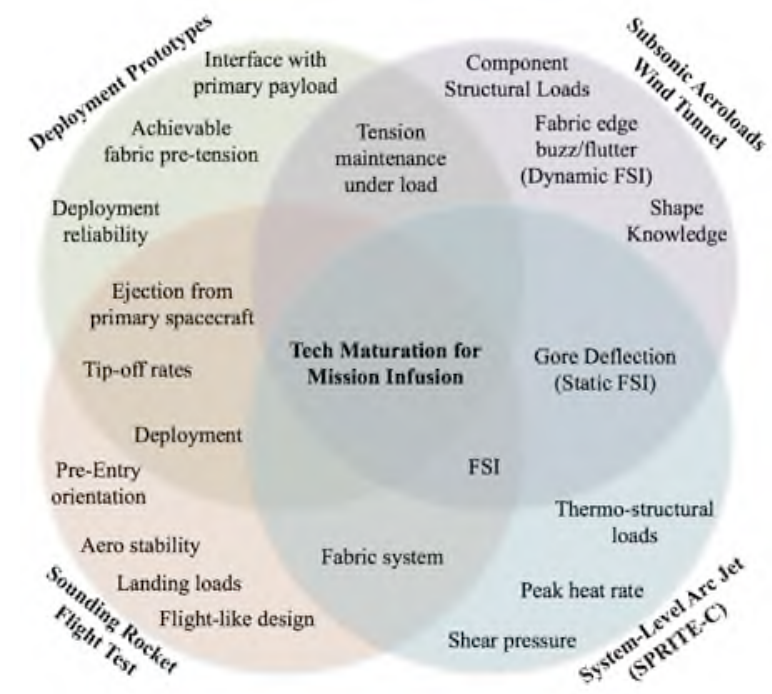

Figure 34. Nano-ADEPT Technology Maturation Strategy [2].
Appendix A. Test Matrix (Selected Points)

\begin{tabular}{|c|c|c|c|c|}
\hline Setting & $\begin{array}{c}\text { Run } \\
\text { ID }\end{array}$ & $\begin{array}{c}\text { Test } \\
\text { Point }\end{array}$ & $\begin{array}{c}\text { AoA } \\
\text { Target }\left({ }^{\circ}\right)\end{array}$ & $\begin{array}{c}\text { Q Targe } \\
\text { (psf) }\end{array}$ \\
\hline $20 \mathrm{lb}$ nut setting & 113 & 5 & 0 & 10 \\
\hline $20 \mathrm{lb}$ nut setting & 113 & 8 & 0 & 10 \\
\hline $20 \mathrm{lb}$ nut setting & 113 & 9 & 0 & 20 \\
\hline $20 \mathrm{lb}$ nut setting & 113 & 10 & 0 & 50 \\
\hline $20 \mathrm{lb}$ nut setting & 113 & 11 & 0 & 75 \\
\hline $20 \mathrm{lb}$ nut setting & 113 & 12 & 0 & 100 \\
\hline $20 \mathrm{lb}$ nut setting & 113 & 13 & 0 & 0 \\
\hline $20 \mathrm{lb}$ nut setting & 114 & 3 & 0 & 0 \\
\hline $20 \mathrm{lb}$ nut setting & 114 & 4 & 0 & 10 \\
\hline $20 \mathrm{lb}$ nut setting & 114 & 5 & 0 & 20 \\
\hline $20 \mathrm{lb}$ nut setting & 114 & 6 & 0 & 50 \\
\hline $20 \mathrm{lb}$ nut setting & 114 & 7 & 0 & 75 \\
\hline $20 \mathrm{lb}$ nut setting & 114 & 8 & 0 & 100 \\
\hline $20 \mathrm{lb}$ nut setting & 114 & 9 & 0 & 75 \\
\hline $20 \mathrm{lb}$ nut setting & 114 & 10 & 0 & 50 \\
\hline $20 \mathrm{lb}$ nut setting & 114 & 11 & 0 & 0 \\
\hline $20 \mathrm{lb}$ nut setting & 116 & 3 & -20 & 0 \\
\hline $20 \mathrm{lb}$ nut setting & 116 & 4 & -20 & 10 \\
\hline $20 \mathrm{lb}$ nut setting & 116 & 5 & -20 & 20 \\
\hline $20 \mathrm{lb}$ nut setting & 116 & 6 & -20 & 50 \\
\hline $20 \mathrm{lb}$ nut setting & 116 & 7 & -20 & 75 \\
\hline $20 \mathrm{lb}$ nut setting & 116 & 8 & -20 & 100 \\
\hline $20 \mathrm{lb}$ nut setting & 116 & 9 & -20 & 75 \\
\hline $20 \mathrm{lb}$ nut setting & 116 & 10 & -20 & 50 \\
\hline $20 \mathrm{lb}$ nut setting & 116 & 11 & -20 & 0 \\
\hline $20 \mathrm{lb}$ nut setting & 118 & 3 & 20 & 0 \\
\hline $20 \mathrm{lb}$ nut setting & 118 & 4 & 20 & 10 \\
\hline $20 \mathrm{lb}$ nut setting & 118 & 5 & 20 & 20 \\
\hline $20 \mathrm{lb}$ nut setting & 118 & 6 & 20 & 50 \\
\hline $20 \mathrm{lb}$ nut setting & 118 & 7 & 20 & 75 \\
\hline $20 \mathrm{lb}$ nut setting & 118 & 8 & 20 & 100 \\
\hline $20 \mathrm{lb}$ nut setting & 118 & 9 & 20 & 90 \\
\hline $20 \mathrm{lb}$ nut setting & 118 & 10 & 20 & 75 \\
\hline $20 \mathrm{lb}$ nut setting & 118 & 11 & 20 & 0 \\
\hline $20 \mathrm{lb}$ nut setting & 119 & 3 & 0 & 0 \\
\hline $20 \mathrm{lb}$ nut setting & 119 & 4 & 0 & 10 \\
\hline $20 \mathrm{lb}$ nut setting & 119 & 5 & 0 & 20 \\
\hline $20 \mathrm{lb}$ nut setting & 119 & 6 & 0 & 50 \\
\hline $20 \mathrm{lb}$ nut setting & 119 & 7 & 0 & 75 \\
\hline $20 \mathrm{lb}$ nut setting & 119 & 8 & 0 & 100 \\
\hline $20 \mathrm{lb}$ nut setting & 119 & 9 & 0 & 90 \\
\hline $20 \mathrm{lb}$ nut setting & 119 & 10 & 0 & 50 \\
\hline $20 \mathrm{lb}$ nut setting & 119 & 11 & 0 & 0 \\
\hline $20 \mathrm{lb}$ nut setting & 120 & 3 & -20 & 0 \\
\hline $20 \mathrm{lb}$ nut setting & 120 & 4 & -20 & 10 \\
\hline $20 \mathrm{lb}$ nut setting & 120 & 5 & -20 & 20 \\
\hline $20 \mathrm{lb}$ nut setting & 120 & 6 & -20 & 50 \\
\hline $20 \mathrm{lb}$ nut setting & 120 & 7 & -20 & 75 \\
\hline $20 \mathrm{lb}$ nut setting & 120 & 8 & -20 & 90 \\
\hline $20 \mathrm{lb}$ nut setting & 120 & 9 & -20 & 75 \\
\hline $20 \mathrm{lb}$ nut setting & 120 & 10 & -15 & 75 \\
\hline $20 \mathrm{lb}$ nut setting & 120 & 11 & -10 & 75 \\
\hline $20 \mathrm{lb}$ nut setting & 120 & 12 & -5 & 75 \\
\hline $20 \mathrm{lb}$ nut setting & 120 & 13 & 0 & 75 \\
\hline $20 \mathrm{lb}$ nut setting & 120 & 14 & 5 & 75 \\
\hline $20 \mathrm{lb}$ nut setting & 120 & 15 & 10 & 75 \\
\hline $20 \mathrm{lb}$ nut setting & 120 & 16 & 15 & 75 \\
\hline $20 \mathrm{lb}$ nut setting & 120 & 17 & 20 & 75 \\
\hline $20 \mathrm{lb}$ nut setting & 120 & 18 & 20 & 90 \\
\hline $20 \mathrm{lb}$ nut setting & 120 & 19 & 20 & 75 \\
\hline $20 \mathrm{lb}$ nut setting & 120 & 20 & 20 & 50 \\
\hline $20 \mathrm{lb}$ nut setting & 120 & 21 & 20 & 20 \\
\hline $20 \mathrm{lb}$ nut setting & 120 & 22 & 20 & 10 \\
\hline $20 \mathrm{lb}$ nut setting & 120 & 23 & 20 & 0 \\
\hline $10 \mathrm{lb}$ nut setting & 122 & 3 & 0 & 0 \\
\hline $10 \mathrm{lb}$ nut setting & 122 & 4 & 0 & 10 \\
\hline $10 \mathrm{lb}$ nut setting & 122 & 5 & 0 & 20 \\
\hline $10 \mathrm{lb}$ nut setting & 122 & 6 & 0 & 50 \\
\hline $10 \mathrm{lb}$ nut setting & 122 & 7 & 0 & 75 \\
\hline $10 \mathrm{lb}$ nut setting & 122 & 8 & 0 & 100 \\
\hline $10 \mathrm{lb}$ nut setting & 122 & 9 & 0 & 90 \\
\hline $10 \mathrm{lb}$ nut setting & 122 & 10 & 0 & 75 \\
\hline $10 \mathrm{lb}$ nut setting & 122 & 11 & 0 & 0 \\
\hline
\end{tabular}




\begin{tabular}{|c|c|c|c|c|}
\hline $5 \mathrm{lb}$ nut setting & 137 & 8 & 0 & 100 \\
\hline $5 \mathrm{lb}$ nut setting & 137 & 9 & 0 & 90 \\
\hline $5 \mathrm{lb}$ nut setting & 137 & 10 & 0 & 75 \\
\hline $5 \mathrm{lb}$ nut setting & 137 & 11 & 0 & 0 \\
\hline Asymmetric & 141 & 3 & -20 & 0 \\
\hline Asymmetric & 141 & 4 & -20 & 10 \\
\hline Asymmetric & 141 & 5 & -20 & 20 \\
\hline Asymmetric & 141 & 6 & -20 & 50 \\
\hline Asymmetric & 141 & 7 & -20 & 75 \\
\hline Asymmetric & 141 & 8 & -20 & 100 \\
\hline Asymmetric & 141 & 9 & -20 & 90 \\
\hline Asymmetric & 141 & 10 & -20 & 75 \\
\hline Asymmetric & 141 & 11 & -15 & 75 \\
\hline Asymmetric & 141 & 12 & -10 & 75 \\
\hline Asymmetric & 141 & 13 & -5 & 75 \\
\hline Asymmetric & 141 & 14 & 0 & 75 \\
\hline Asymmetric & 141 & 15 & 5 & 75 \\
\hline Asymmetric & 141 & 16 & 10 & 75 \\
\hline Asymmetric & 141 & 17 & 15 & 75 \\
\hline Asymmetric & 141 & 18 & 20 & 75 \\
\hline Asymmetric & 141 & 19 & 20 & 90 \\
\hline Asymmetric & 141 & 20 & 20 & 100 \\
\hline Asymmetric & 141 & 21 & 20 & 75 \\
\hline Asymmetric & 141 & 22 & 20 & 50 \\
\hline Asymmetric & 141 & 23 & 20 & 20 \\
\hline Asymmetric & 141 & 24 & 20 & 10 \\
\hline Asymmetric & 143 & 3 & 0 & 0 \\
\hline Asymmetric & 143 & 4 & 0 & 10 \\
\hline Asymmetric & 143 & 5 & 0 & 20 \\
\hline Asymmetric & 143 & 6 & 0 & 50 \\
\hline Asymmetric & 143 & 7 & 0 & 75 \\
\hline Asymmetric & 143 & 8 & 0 & 100 \\
\hline Asymmetric & 143 & 9 & 0 & 90 \\
\hline Asymmetric & 143 & 10 & 0 & 75 \\
\hline Asymmetric & 143 & 11 & 0 & \\
\hline
\end{tabular}

\section{APPENDix B. DAta ReDUCtion}

\section{Strut Load Cells}

Strut load cell data was recorded through a laptop-based DAS and sampled at a rate of 50 samples per second. An ON/OFF channel was connected from the facility DAS and the laptopbased DAS in order to synchronize the data taken by the two systems. An average strut load value was computed by averaging raw data taken over the same time period at which the facility data system was recording.

In order to evaluate the global load distribution over the fabric test article, it is easier to look at the load sum of both struts attached to a given rib. This paper discusses "strut loads" as the sum of both strut load cells that are attached to a given rib. Some example strut load data is displayed below in Figure 35. This "radar" plot shows the sum of the two strut loads attached to each rib, referred to as R1 through R8. Data from five different test points are shown on this particular figure. The spider-web-like isolines are lines of constant force where the concentric isolines are spaced in increments of $10 \mathrm{lbf}$ and the center of the plot is $0 \mathrm{lbf}$. In this specific example, all of these test points are at the same dynamic pressure (75 psf), angle of attack $\left(0^{\circ}\right)$, and tension nut setting (20 lbf/nut setting). The figure shows that the struts attached to each rib are loaded in compression at about $80 \mathrm{lbf}$ (or about $40 \mathrm{lbf}$ per strut). The chronological order at which each test point was taken is given in the legend (first through fifth). A small but detectable amount of fabric relaxation is evident in the strut load data shown in this figure. The strut loads have reduced by a few pounds by the fifth time this test point is taken. This is consistent with the fabric becoming more slack. This method 
of representing the strut load data also gives an intuitive picture of load symmetry through the entire structure. There is slightly less load through the struts attached to rib R1 compared to the rest of the ribs. Rib R1 is located between the $0^{\circ}$ gore and the $45^{\circ}$ gore in this example.
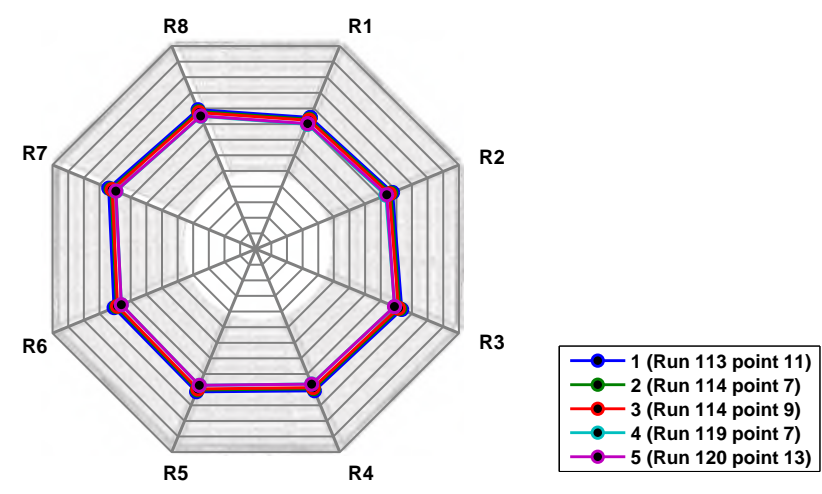

Figure 35. Example plot of strut load data showing five chronological data points at the same test condition (20 lbf/in nut setting, $0^{\circ} \mathrm{AoA}, 75 \mathrm{psf}$ ). Isoline $=10 \mathrm{lbf}$. Center of figure $=0$ lbf.

\section{String Potentiometers}

String potentiometer data was recorded by the same laptopbased DAS as the strut load cells and sampled at a rate of 50 samples per second. The raw string potentiometer data was post-processed to compute a single value of string displacement for each gore at a given test point. This requires setting a zero value for each string potentiometer from which a displacement can be computed (note that the "zero" for a given string potentiometer data set consists of eight zero values, one for each string potentiometer). Unfortunately setting a zero is not straightforward for several reasons. First, most runs involved setting the test article at a given angle of attack and then taking data as dynamic pressure was increased. After the peak dynamic pressure was reached, dynamic pressure was reduced and data was taken at a few points along the way down to capture repeat data. As will be expanded on later in this paper, there is a significant amount of hysteresis in the gore deflection as dynamic pressure is reduced. Second, the instrumentation section of this paper described how the string potentiometer is mounted to the central moving ring, which translates in order to change the tension in the fabric. This means that in order to compare string potentiometer data between tension settings in a true apples-to-apples sense, the change in string potentiometer length due to movement of the ring must be considered. Third, in several cases there was manual manipulation of the fabric in between runs as part of the inspection process. Finally, no string potentiometer data was taken at the first test point of $0 \mathrm{psf}$ due to a data system error.

Despite these difficulties related to finding the string potentiometer zeros, the data is still useful for making qualitative assessments of test article performance. The following example will serve as an explanation of how to interpret the string potentiometer data included in this paper. String potentiometer data using three different zeroing strategies is shown below in Figure 36. The three data sets are shown on "radar plots" that display the data from a given string potentiometer along an axis coincident with the midgore of each corresponding rib. Behind the plot is a transparent figure of the Nano-ADEPT OML to help orient the reader. Note that this is the same plotting method technique used to display data from the strut load cells. The isoline increment for all of the string potentiometer radar plots in this paper is 0.025 in. It is critical to note that string displacements do not equal gore deflections because the string is not perpendicular to the gore. Photogrammetry data are used to ascertain absolute gore deflections. The displacement value at the center of the radar plot is zero along all eight axes.

The three plots were generated with the same raw string potentiometer data. This example is from Run 132, which was a dynamic pressure $(\mathrm{Q})$ sweep on the $5 \mathrm{lbf} /$ in nut setting at $0^{\circ}$ AoA. As can be seen in Appendix A, the dynamic pressure was increased from $0 \mathrm{psf}$ to $100 \mathrm{psf}$ and reduced back to $0 \mathrm{psf}$ with data taken in the following order: 10, 20, 50, 75, 100, 90, 75 , and $0 \mathrm{psf}$. The data below are four test points taken while increasing Q $(20,50,75$, and $100 \mathrm{psf})$. In each radar plot a different zero technique was used, defined here:

Zero Strategy 1 (ZS1): All data use the same zero taken from Run 113 at 10 psf. This was the first string potentiometer data point recorded.

Zero Strategy 2 (ZS2): Each run uses its own zero computed from the first test point for that run. In all cases this corresponds to the $10 \mathrm{psf}$ condition as $\mathrm{Q}$ is increased.

Zero Strategy 3 (ZS3): One zero is determined for each tension setting and used for all subsequent runs at that tension setting.

The three zero strategies are simply three different ways to look at the same data set. ZS1 is most useful for comparing overall deflection trends across the entire data set. For example, this zero strategy can be used to compare sensitivity of deflection to angle of attack and dynamic pressure at different tension settings. Some error is introduced because the string potentiometers are attached to the moving ring. ZS2 gives the best depiction of the relative displacement between different gores within a given run. Because the zero is set at the beginning of each run at $10 \mathrm{psf}$, the displacement values clearly show delta displacements between the different gores. The strange shape of this plot is because at low-tension settings there was a lot of deflection at low dynamic pressures and then a small amount of change as dynamic pressure was increased from $10 \mathrm{psf}$ to $100 \mathrm{psf}$. In other words, this plot is showing small changes from a large initial deflection. Because most of the deflection had already occurred by $10 \mathrm{psf}$ (the zero value for this case), only the small changes are apparent in the string potentiometer data. Finally, ZS3 is most useful for comparing displacement between runs of a given tension setting. Because Run 132 was the first run of the $5 \mathrm{lbf} / \mathrm{in}$ nut setting, this plot is identical to the ZS2 plot. These zero strategies are used as described to communicate a particular result from the wind tunnel test since no single zero strategy is effective at showing the overall trends. 

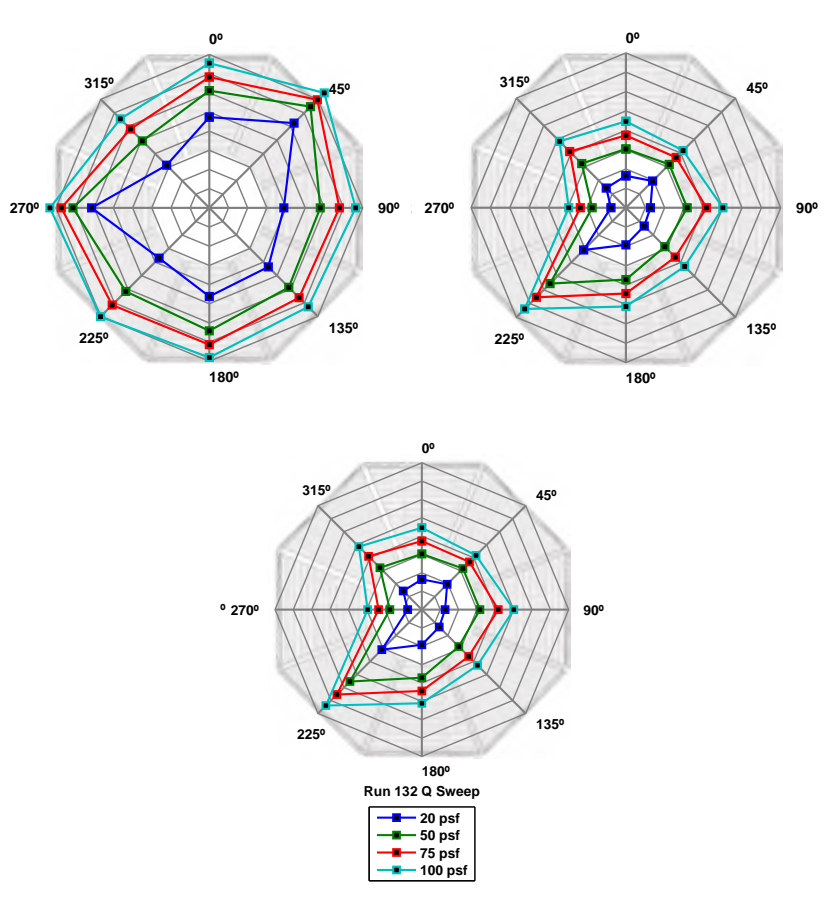

Figure 36. String displacement data from Run 137 plotted using Zero Strategy 1 (top left), Zero Strategy 2 (top right), and Zero Strategy 3 (bottom). Isoline $=\mathbf{0 . 0 2 5}$ in. Center of figure $=0$ in.

\section{Photogrammetry}

The software provided with the photogrammetry system was used to generate 3D displacement maps. Due to the location of the photogrammetry cameras, quality data was only generated for the $45^{\circ}, 90^{\circ}$, and $135^{\circ}$ gores. It was possible at some angles to capture data from other gores on the model however the coverage on these gores is of compromised quality. The 3D deflection maps are useful for investigating global deflection phenomena as will be discussed in the following section.

It is evident in the photogrammetry data that forces on the test article cause the entire model to move with increasing dynamic pressure as a result of rigid body motion. The sting actually deflects by a small amount as the dynamic pressure increases. This presents an additional complication when trying to compute a fabric deflection since the "known" zero surfaces are moving with increasing dynamic pressure (such as the rigid nose and the ribs). In order to compute a single value of gore deflection for some cases of interest, displacement data from photogrammetry were post-processed at the string potentiometer anchor locations. The deformed shapes were transferred to a CAD program and processed individually. As depicted in Figure 37, the deflection of a given gore, $\delta$, is computed as the distance between an ideal plane intersecting both ribs attached to the gore and the deflected gore shape from photogrammetry. This provides a single value of deflection for each gore, which is used in this paper to explore deflection trends as a function of pre-tension and dynamic pressure. The deflections noted in this paper were obtained as the average of at least seven images for each 30 -second test point. Displacement error is computed as 1/30,000 of the field of view. Taking into account that the system was calibrated to have a field of view of 28.35 in to capture the full width of the test article $(\sim 25 \mathrm{in})$, the error is $28.35 \mathrm{in} / 30,000= \pm 9.4510^{-4}$ in.

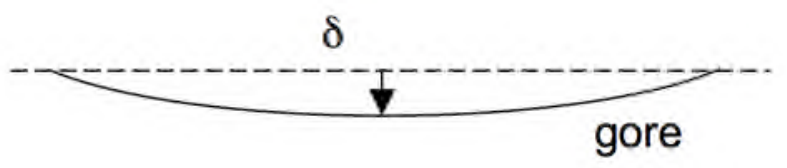

Figure 37. Definition of gore deflection calculated from photogrammetry.

\section{ACKNOWLEDGEMENTS}

We wish to acknowledge Ames Chief Technologist Harry Partridge for funding the Center Innovation Fund that sparked development of Nano-ADEPT and provided partial funding for this wind tunnel test. We also would like to thank the Space Technology Mission Directorate's (STMD) Game Changing Development Program (GCDP) who provided bridge funds to make this test possible. We wish to thank the entire team of Ames technicians who worked to fabricate this hardware on a tight schedule and even make modifications at the last minute when issues were found. We wish to thank the team of US Army technicians at the $7 \times 10$ Foot Wind Tunnel whose expertise made this test a success: Stephen Nance, Bruce Gesek, Sameera Gunatileka, and Brian Chan. Finally, we wish to thank Maxim de Jong of Thin Red Line Aerospace for his excellent craftsmanship and on-site support during the wind tunnel test.

\section{REFERENCES}

[1] "NASA Technology Roadmaps TA 9 : Entry, Descent , and Landing Systems," July, 2015.

[2] B. Smith, A. Cassell, C. Kruger, C. Kazemba, and K. Simonis, "An Entry System for Secondary Payloads," IEEE Aerospace Conference, March 2015.

[3] B. Smith, E. Venkatapathy, P. Wercinski, B. Yount, D. Prabhu, P. Gage, L. Glaze, and C. Baker, "Venus in Situ Explorer Mission design using a mechanically deployed aerodynamic decelerator," IEEE Aerospace Conference, March 2013.

[4] J. Ross and N. Burnside, "Unsteady Pressures on a Generic Capsule Shape," 53rd AIAA Aerospace Sciences Meeting, January 2015, pp. 1-11.

\section{BIOGRAPHY}

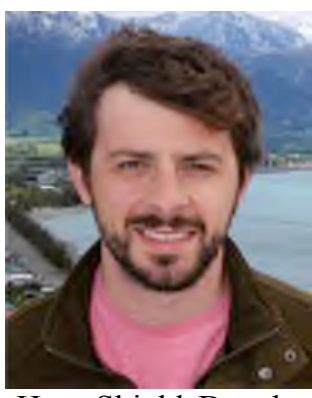

Brandon Smith has been with the Entry Systems and Vehicle Development Branch of NASA Ames Research Center since 2011. Prior to joining NASA, Brandon received his B.S. and M.S. in aerospace engineering from Georgia Institute of Technology. In addition to his work on ADEPT, Brandon was a system engineer for the Orion Exploration Flight Test 1 (EFT-1) Heat Shield Developmental Flight Instrumentation (DFI) and is currently the Deputy Project Manager for heatshield DFI on Orion Exploration Mission One (EM1). 